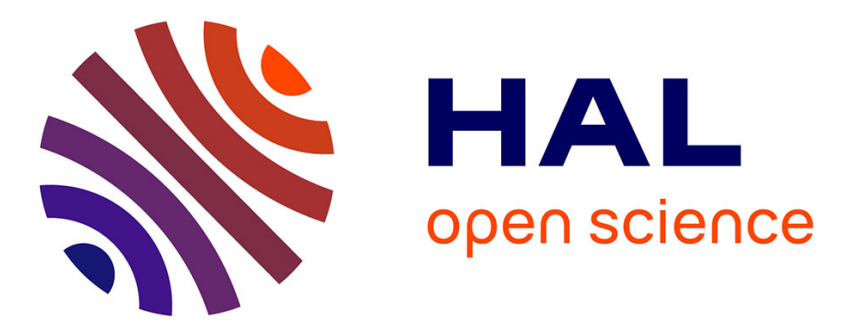

\title{
An autonomous plant growing miniaturized incubator for a Cubesat
}

Christophe Marcel Trouillefou, Yann-Seing Law-Kam Cio, Mario Jolicoeur, Bilel Said, Anne Galarneau, Sofiane Achiche, Giovanni Beltrame

\section{To cite this version:}

Christophe Marcel Trouillefou, Yann-Seing Law-Kam Cio, Mario Jolicoeur, Bilel Said, Anne Galarneau, et al.. An autonomous plant growing miniaturized incubator for a Cubesat. Acta Astronautica, 2021, 179, pp.439-449. 10.1016/j.actaastro.2020.11.009 . hal-03026031

\section{HAL Id: hal-03026031 https://hal.science/hal-03026031}

Submitted on 26 Nov 2020

HAL is a multi-disciplinary open access archive for the deposit and dissemination of scientific research documents, whether they are published or not. The documents may come from teaching and research institutions in France or abroad, or from public or private research centers.
L'archive ouverte pluridisciplinaire HAL, est destinée au dépôt et à la diffusion de documents scientifiques de niveau recherche, publiés ou non, émanant des établissements d'enseignement et de recherche français ou étrangers, des laboratoires publics ou privés. 


\title{
An autonomous plant growing miniaturized incubator for a Cubesat
}

\author{
Christophe Marcel Trouillefou ${ }^{a, *}$, Yann-Seing Law-Kam Cio ${ }^{b}$, Mario Jolicoeur ${ }^{c}$, Bilel Said ${ }^{d}$, \\ Anne Galarneau ${ }^{\mathrm{d}}$, Sofiane Achiche ${ }^{\mathrm{b}}$, Giovanni Beltrame ${ }^{\mathrm{a},}$ \\ a Department of Computer and Software Engineering, Ecole Polytechnique de Montréal, \\ 2500, chemin de Polytechnique, H3T 1J4, Montréal, Canada \\ b Department of Mechanical Engineering, Ecole Polytechnique de Montréal, \\ 2500, chemin de Polytechnique, H3T 1J4, Montréal, Canada \\ c Department of Chemical Engineering, Ecole Polytechnique de Montréal, \\ 2500, chemin de Polytechnique, H3T 1J4, Montréal, Canada \\ d Institut Charles Gerhardt Montpellier, UMR 5253 CNRS, Université de Montpellier, ENSCM, \\ 240 avenue du Professeur Emile Jeanbrau, 34296 Montpellier Cedex 5, France.
}

\begin{abstract}
We developed a $2 \mathrm{U}$ incubator and used it to grow the legume Medicago truncatula autonomously. This prototype was designed to become a payload in a $3 \mathrm{U}$ Cubesat nanosatellite; it therefore weighs only $1.2 \mathrm{~kg}$ and has a total consumption of less than 4 Watt. The incubator is equipped with many sensors to monitor its environment such as gas, humidity and heat sensors. It also contains actuators to modify the environment such as a flexible heater and a $\mathrm{TiO}_{2}$-based ethylene photocatalyst to remove plants ethylene production. The objectives are first to determine good growth conditions in this limited volume device and to allow better prototyping of a $2 \mathrm{U}$ incubator experiment. Second, to build a prediction model based on measurements of plants functional traits. Therefore, first we carried out a design of experiments to perform the germination and growth of $M$. truncatula at temperatures of $22^{\circ} \mathrm{C}$ and $29^{\circ} \mathrm{C}$, under $\mathrm{CO}_{2}$ concentrations of $380 \mathrm{ppm}$ and $10000 \mathrm{ppm}$ and with two photoperiod regimes $16 \mathrm{~h} / 8 \mathrm{~h}$ and $20 \mathrm{~h} / 4 \mathrm{~h}$. This gives a total of 8 experimental conditions tested in large climatic chambers during a 30-day period. The $2 \mathrm{U}$ experiment was performed at $26^{\circ} \mathrm{C}, 380 \mathrm{ppm} \mathrm{CO}_{2}$ and with a $20 \mathrm{~h} / 4 \mathrm{~h}$ photoperiod. This experiment lasted 62 days before being stopped to find that 2 large plants had grown for almost 52 days. Secondly, by using a principal components analysis, we observed that most of the plants functional traits variables explained the variability on the first principal component, with the exception of the surface area of the small leaves and the quantity of small leaves which explained the variability on the second principal component. The quantity of big leaves, which is an easily measurable variable with a camera, was very strongly correlated with the first principal component. These 3 variables and 2 others were included in the model equations used to predict the values of visible and hidden plants functional traits. This model has been successfully tested on the $2 \mathrm{U}$ incubator experiment allowing precise determination of fresh weight biomass under $20 \%$ error. The determination of the fresh weight of the roots, the fresh weight of the shoots, the amount of big and small leaves, the total amount of leaves, the surface area of big leaves and small leaves and the total surface area of the leaves was carried out.
\end{abstract}

Keywords: Life support system, Autonomous incubator, Cubesat, Medicago truncatula, Plant functional traits, Prediction model.

\footnotetext{
- Corresponding authors.

Email addresses: christophe.trouillefou@gmail.com (Christophe Marcel Trouillefou), giovanni.beltrame@polymtl.ca (Giovanni Beltrame).
} 


\section{Introduction}

The development of an autonomous life support systems in a Cubesat nanosatellite fits into a larger and expanding context of scientific research on plant cultivation in microgravity. Among them, controlled ecological life support systems are the most sophisticated design of autonomous ecosystems that could provide efficiently and sustainably water, oxygen, and food to astronauts [1]. However, despite the fact that plant growth systems have been studied for more than 40 years now [2], we are not at a stage where we can produce daily fresh food for the inhabitants of the international space station for example.

This project includes two major axes: - The development of a growth experiment of a legume in the prototype incubator. - The design of an intelligent automation system, which learns from experiments carried out on Earth and can carry out any sort of culture autonomously. The results presented here concern the first axis.

We designed an automated miniature plant growth device and conducted many experiments on the germination and growth of Medicago truncatula, which is a diploïd autogamous model for leguminous plants [3]. Our original goal was to let the plants live a full 3 month cycle from seed to seed. Germination and growth tests were carried out both in spacious incubators to determine effective growth parameters. Afterwards, experiments were performed in the $2 \mathrm{U}$ incubator to test the validity of the operation of this intensive growth device.

A model was set up to help predict values of plants functional traits such as the total biomass or root biomass by using experimental data gotten from the measurements of visible functional traits during a trial. Indeed, it can be useful to have an estimate of certain characteristics of hidden organs, such as roots to better design their container and comprehend the overall state of the plants.

While testing a cultivation method for the production of a legume, we explored another approach for the technical development of miniaturized incubators and we conceived a new design of autonomous plant cultivation systems in microgravity. Indeed, the tendency is to create bigger space plant growth chambers; however, we chose to develop the smallest incubator ever to fit it into a CubeSat nanosatellite [2]. On the other hand, many biological experiments are currently carried out in the ISS, but they all require human intervention to direct them because they are not fully autonomous. Therefore, this $2 \mathrm{U}$ incubator is a basis that could help the next generation of autonomous small plant production systems by using mini incubators to perform autonomous germination and growing tests with different species at a very low cost $(<\$ 700 \mathrm{US})$. All these assembled developments described in this article are part of the Spacebean project which is still under development.

\section{Materials and methods}

\subsection{Biological material}

Sterile scarified seeds of Medicago truncatula L. Jemalong strain A17 (from INRA, Mauguio, France) were used to perform all the plant experiments [4].

\subsection{Plant experiment in climatic chambers}

We grew plants into large incubators: the SCO40 (ShelOLab) and the Ultima II (Revco). These climatic chambers have different sizes, but both are $\mathrm{CO}_{2}$ incubators with close sensing capabilities that satisfy the range of measurement required in the plant experiment (Table 1). 
Table 1: parameters of the climatic chambers used in the plant experiment.

\begin{tabular}{lcc}
\hline & SCO40 & Ultima II \\
Volume (L) & 1117 & 165 \\
Temperature range ( $\left.{ }^{\circ} \mathrm{C}\right)$ & $8-60$ & $5-60$ \\
Temperature sensitivity ( $\left.{ }^{\circ} \mathrm{C}\right)$ & 0.1 & 0.1 \\
CO2 range (\%) & $0-20$ & $0-20$ \\
CO2 sensitivity (\%) & 0.1 & 0.1 \\
Relative Humidity upper limit (\%) & n.a & 96 \\
Relative Humidity sensitivity (\%) & n.a. & 1 \\
Relative Humidity control & Water pan & Water pan \\
\hline
\end{tabular}

The plant experiment in climatic chambers (PECC) allowed to analyze plants functional traits and behaviour when grown under various experimental conditions. Therefore, two main objectives were followed: (objective 1) determine the most important parameters to grow $M$. truncatula in the $2 \mathrm{U}$ incubator. (objective 2) collect data on plant functional traits to feed a prediction model.

- Objective 1:

As shown in Table 2, three variables were considered: temperature, photoperiod, and $\mathrm{CO}_{2}$ concentration. Humidity was controlled passively by placing a water pan in the incubator. The temperature and $\mathrm{CO}_{2}$ concentration were controlled by the internal incubators sensors and actuators. During the 90 minutes Earth orbiting, the maximum temperature estimated inside the incubator [5] will reach $30^{\circ} \mathrm{C}$ when the CubeSat will be exposed to the Sun. Indeed, the satellite will do a 90 minutes Earth orbiting travel, so to avoid heat stress from such a short time frame, we have chosen a maximum temperature of $29.5^{\circ} \mathrm{C}$.

Table 2: Variables used in the design of experiment.

\begin{tabular}{lllll}
\hline Temperature & $22.5^{\circ} \mathrm{C}$ & (T1) & $29.5^{\circ} \mathrm{C}$ & (T2) \\
Photoperiod & $16 \mathrm{~h} / 8 \mathrm{~h}$ & (P1) & $20 \mathrm{~h} / 4 \mathrm{~h}$ & (P2) \\
$\mathrm{CO}_{2}$ concentration & $380 \mathrm{ppm}$ & (C1) & $10000 \mathrm{ppm}$ & $(\mathrm{C} 2)$ \\
\hline
\end{tabular}

The combination of these variables gives 8 experimental conditions written Cdt1, Cdt2, Cdt 3 and Cdt4 (Table 3). The experiments were carried out in two stages. First Series1 was performed, then Series2. Each series correspond to a temperature tested: first test at $22.5^{\circ} \mathrm{C}$ (Series1) and second at $29.5^{\circ} \mathrm{C}$ (Series2). Each climatic chamber correspond to a $\mathrm{CO}_{2}$ concentration tested: $\mathrm{Cdt} 1$ and $\mathrm{Cdt} 2$ were at $380 \mathrm{ppm} \mathrm{CO} 2$ (Ultima II) and Cdt3 and Cdt4 were at $10000 \mathrm{ppm} \mathrm{CO} 2$ (SCO40). Finally, as described in Table 3, the two photoperiods were tested in each climatic chamber.

Table 3: Description of the series and the experimental conditions tested

\begin{tabular}{lllll}
\multicolumn{5}{c}{ Table 3: Description of the senes and the expenmental conditions tested. } \\
\hline \multirow{2}{*}{ Series 1} & $\mathrm{Cdt} 1$ & $\mathrm{Cdt} 2$ & $\mathrm{Cdt} 3$ & $\mathrm{Cdt} 4$ \\
Series 2 & $\mathrm{~T} 1 / \mathrm{Cl} 1 / \mathrm{P} 1$ & $\mathrm{Tl} / \mathrm{Cl} / \mathrm{P} 2$ & $\mathrm{Tl} / \mathrm{C} 2 / \mathrm{P} 1$ & $\mathrm{~T} 1 / \mathrm{C} 2 / \mathrm{P} 2$ \\
& $\mathrm{~T} 2 / \mathrm{Cl} 1 / \mathrm{Pl}$ & $\mathrm{T} 2 / \mathrm{Cl} / \mathrm{P} 2$ & $\mathrm{~T} 2 / \mathrm{C} 2 / \mathrm{Pl}$ & $\mathrm{T} 2 / \mathrm{C} 2 / \mathrm{P} 2$ \\
\hline
\end{tabular}

Triplicates were realised for each condition. We used 3 cylindrical plastic dishes containing 6 scarified seeds into $80 \mathrm{~g}$ sand (cas: $14808-60-7$ ), $24 \mathrm{mg}$ synthesized goethite and $26 \mathrm{ml}$ nutrient solution. The mineral nutrient solution was composed of $\mathrm{KNO}_{3}(3.94 \mathrm{mM}), \mathrm{KH}_{2} \mathrm{PO}_{4}(143$ $\mu \mathrm{M}), \mathrm{CaCl}_{2}(2.76 \mathrm{mM}), \mathrm{FeEDDHA}(6 \mu \mathrm{M}), \mathrm{MgSO}_{4}(7.88 \mathrm{mM})$ and for the micronutrient of $\mathrm{H}_{3} \mathrm{BO}_{3}(443 \mu \mathrm{M}),\left(\mathrm{NH}_{4}\right)_{6} \mathrm{MoO}_{7} \mathrm{O}_{24}(3 \mu \mathrm{M}), \mathrm{ZnSO}_{4}(148 \mu \mathrm{M}), \mathrm{MnSO}_{4}(177 \mu \mathrm{M}), \mathrm{CuSO}_{4}(39$ $\mu \mathrm{M})$. All dishes were covered by a sterile membrane (AeraSeal film) with 6 tiny holes to 
allow the passage of the stem. Watering was done using a syringe equipped with a $0.2 \mu \mathrm{m}$ filter and a needle. Total duration of each series was 4 weeks.

- Objective 2:

After harvesting the plants and gathering the data, we computed ${ }^{1}$ the coefficients of a set of polynomial multivariate regression equations that best fit fresh weight biomass using the data of Series 2 to create a model. For each equation, we calculated the error using the root mean square percentage error (RMSPE) formula $\sqrt{\frac{1}{n} \sum_{1}^{n}\left(\frac{\left(F W B_{\text {moas }}-F W B_{c a l}\right)}{F W B_{\text {moss }}}\right)^{2}}$, where $F W B$ represents the Fresh Weight Biomass, cal means calculated and meas means measured. To validate the model, we used the equations that minimize the error below 0.2 (c.f. section 3.3 , Model) with the data obtained from Series 1 and $2 \mathrm{U}$ incubator experiments.

\subsubsection{Plant measurements}

Plant functional traits are variables whose measured data is used to perform statistical analyzes and to feed a prediction model. The variables used and their abbreviations are as follows: fresh weight biomass (FWB), fresh weight of roots (FWR), fresh weight of shoot (FWS), quantity of big and small leaves (BL and SL), total quantity of leaves (TL), surface area of big leaves and small leaves (SBL and SSL) and total surface area of leaves (STL).

\section{- Biomasses}

At the end of each experiment, the shoot was separated from the root by cutting each plant at the collar. The shoot was weighed to obtain the fresh weight of the shoot. The soil was removed from the Petri dishes by washing it with distilled water so that only the root system remains. Then the roots were placed on paper to absorb the excess water before being weighed in turn to obtain the fresh weight of the roots. The sum of the two corresponding masses gave us the fresh weight biomass of a plant.

\section{- Leaf classification and surface area determination}

After weighing the shoots and roots, the leaves were counted and classified into small and big leaves. Based on the correlation coefficient between the size of the longest leaflet and the fresh weight biomass, we decided that leaves that have a leaflet greater than or equal to $5.5 \mathrm{~mm}$ would be classified as large leaves. (SUPPL. 1, Figure 10). Using this criterion, we were able to determine the amount of big leaves and small leaves.

The surface area of leaf petals was determined using the method and equations described in SUPPL. 1, Figure 11.

\subsection{The $2 U$ incubator experiment}

The choice of the growth conditions in the $2 \mathrm{U}$ incubator was the result of a consensus between the different options tested. This choice is not optimal, but rather secure. Indeed, the advantages of a high temperature $\left(29^{\circ} \mathrm{C}\right)$ in terms of speed of germination and quantity of plants are opposed to that of a lower temperature $\left(22^{\circ} \mathrm{C}\right)$ where we obtained the greatest biomasses. High $\mathrm{CO}_{2}$ concentration gave plants of small size and mass. Finally, the photoperiods tested at $29^{\circ} \mathrm{C}$. did not give any significant difference between the plants obtained. Therefore we chose the longest lighting period $(20 \mathrm{~h} / 4 \mathrm{~h})$, with a low concentration of $\mathrm{CO}_{2}(380 \mathrm{ppm})$ and an intermediate temperature $\left(26^{\circ} \mathrm{C}\right)$, so they could surely allow the plant to grow within the $640 \mathrm{~cm}^{3}$ available in the growth chamber of the $2 \mathrm{U}$ incubator.

\footnotetext{
${ }^{1} \mathrm{R}$ software : package stats.
} 


\subsubsection{Description of the prototype}

The designed $2 \mathrm{U}$ incubator used in this experiment was 3D printed with PLA. All the slots made for the passage of the wires were clogged with silicone (plasticine, Pebeo). As described in the Figure 1, the incubator contains from bottom to top: a water tank with a capacity of $350 \mathrm{ml}$, a peristaltic pump (RP-Q \& QX, Takasago Fluidic Systems), a packaging for the soil (packsoil), several sensors, a flexible heater (TSA(C)0200040bR7.47, Taiwan KLC Corporation), an ethylene scrubber, a CMOS camera (OV7670) and a set of 4 red led $625 \mathrm{~nm}$ and 4 blue led $475 \mathrm{~nm}$ (Cree XB-D Led, Marktech).

The water tank was 3D printed with PLA and an epoxy coating was added to make it waterproof. Watering was performed once a day following a precise administrated volume calendar (SUPPL. 2, Table 9). The nutrient solution was delivered into the soil through two silica monoliths of $6 \mathrm{~mm}$ diameter and $5 \mathrm{~cm}$ and $7 \mathrm{~cm}$ length. Previous plant growth experiments were performed in ISS using macroporous tubes for root system watering [6]. Our silica monoliths feature have a hierarchical interconnected porosity with mesopores of $10 \mathrm{~nm}$ and homogeneous macropores of $5 \mu \mathrm{m}$ [7] suitable to control precisely their permeability [8] and therefore to precisely control the flow rate and the dispersion of water in the incubator. The monoliths were cladded with a heat shrinkable Teflon gain (FEP AWG 6, Castello France) at $350^{\circ} \mathrm{C}$ for 5 minutes to ensure the connectivity with the pump. Two slots on each side were pitted into the gain to insure the dispersion of the nutrient solution into the entire packsoil. The silica monoliths were synthesized in Montpellier, France, according to Galarneau et al. [7]. The packsoil was 3D printed with PLA and contained $80 \mathrm{~g}$ of sand and two units of monoliths rigidified with a plastic sheath that has two slots, one on each side. The packsoil contains on its top tiny holes for the passage of the stems in front of which there are the seed supports (SUPPL. 2, Figure 12). Upper and bottom parts of the packsoil were covered by the waterproof semi-permeable membrane.

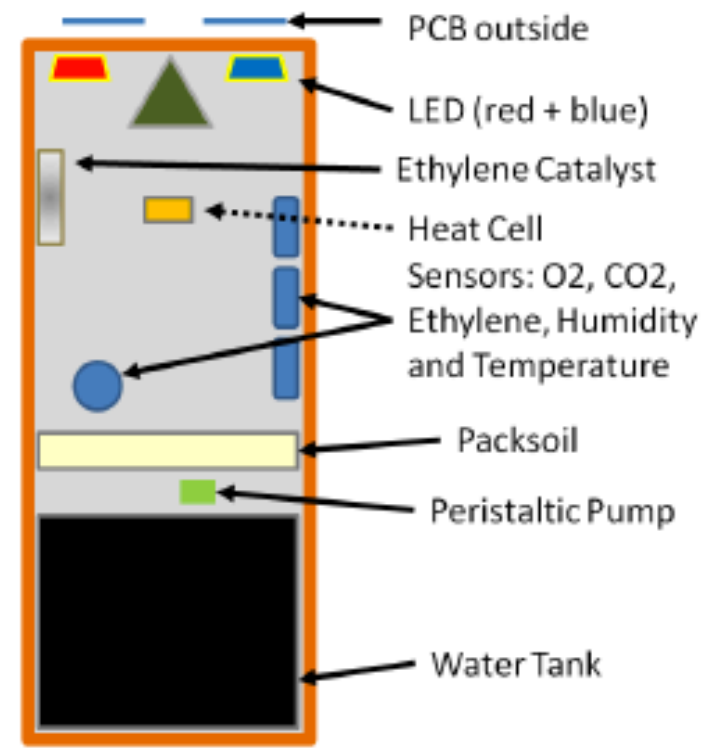

Present Placement $1 \mathrm{G}$

Figure 1: General illustration of the 2U incubator as it was prototyped for the experiment under 1G.

The sensors were $\mathrm{CO}_{2}$ (CCS811, AMS), $\mathrm{O}_{2}$ (O2-G1, Alphasense), $\mathrm{C}_{2} \mathrm{H}_{4}$ (ME3-C2H4, Winsen), Temperature and Humidity (DHT22, Adafruit). The heater was glued on the wall and forced convection was performed by the use of the ethylene scrubber fan. The ethylene 
scrubber performed photocatalysis with a UV light $(370 \mathrm{~nm})$ on a coated plexiglass with $\mathrm{TiO}_{2}$ P25 (cas: 13463-67-7). The dip coating was realized on a striped piece of plexiglass that was dipped and dried 5 times. The dipping solution, composed of $\mathrm{TiO}_{2}$ and MilliQ water (18Mohm) with a concentration of $16 \mathrm{mg} / \mathrm{ml}$, was sonicated for 5 minutes before each dipping. The drying duration was 1 hour at a temperature of $37^{\circ} \mathrm{C}$. The CMOS camera was controlled by an Arduino Uno. An Arduino Mega were programmed: - to control the photoperiod, the temperature regulation, the ethylene scrubber; - to activate the peristaltic pump for watering and - to get instantaneous data values from each sensor once every 30 minutes (Table 4).

\begin{tabular}{|c|c|}
\hline Parameters & Values \\
\hline Light Intensity & $570 \mu \mathrm{mol} \mathrm{m}^{2}-\mathrm{s}^{-1}$ \\
\hline Photoperiod & $20 \mathrm{~h}$ light / 4h obscurity \\
\hline Temperature & $26^{\circ} \mathrm{C}$ \\
\hline Humidity & $>90 \%$ \\
\hline $\mathrm{CO}_{2}$ & 380ppm - 10000ppm \\
\hline $\mathrm{O}_{2}$ & $21 \%+-2$ \\
\hline $\mathrm{C}_{2} \mathrm{H}_{4}$ & $0-5000 \mathrm{ppb}$ \\
\hline Peristaltic pump & $0.0183 \mathrm{ml} / \mathrm{s}$ \\
\hline
\end{tabular}

\section{Results and discussion}

Medicago truncatula is a plant which is able to make symbiotic associations. Some microorganisms are able to fix nitrogen from the air and convert it into nitrates that can be taken in by plants roots. Currently, the ExoLab-7 and ExoLab-8 [9] projects are studying the use of Rhizobium in microgravity on Vigna unguiculata. During these experiments, nodulation are performed by Rhizobium leguminosarum and postflight, root nodules will be analyzed to determine if they were able to fix and transform $\mathrm{N}_{2}$.

Considering the small size of the incubator's growth chamber $(8 \times 8 \times 10) \mathrm{cm}$, we chose to sterilize the seeds to avoid contamination and observe the ability of Medicago truncatula to grow only using the nutrients provided. Indeed, several questions arise regarding the variations in the concentrations of the gas mixture that will take place in the incubator during an experiment lasting 4 months:

- How much $\mathrm{CO}_{2}$ and $\mathrm{O}_{2}$ would we need for the plant alone?

- How much would the concentration of $\mathrm{N}_{2}$ vary after adding Rhizobium leguminosarum, Sinorhizobium meliloti or Azotobacter vinelandii?

To answer the first question, we must first know how the plant works without its symbiotic associations. Mainly, the consumption of gas, nutrients, water and the optimal period of photosynthesis. To answer the second question, symbiotic microorganisms could be inoculated and new experiments carried out in order to assess the consequences on the variation of gases and the demand for nutrients, water and photoperiod. For example, the functioning of Sinorhizobium meliloti nitrogenase, responsible for binding $\mathrm{N}_{2}$, has been shown to consume a lot of $\mathrm{O}_{2}$ when Medicago sativa suffers from phosphorus deficiency [10]. This metabolic function has also been observed in $M$. truncatula when combined with Sinorhizobium meliloti [11]. Stutte et al. demonstrated that $M$. truncatula can form nodules in microgravity through activation of the Enod11::gus gene by Sinorhizobium meliloti. However, this association has been less productive than on Earth, as gene expression appears to be affected by microgravity [12]. 


\subsection{Germination in climatic chambers}

On the third day after heating at the appropriate temperature, different schemes appeared for the conditions tested. In the Figure 2, we can compare the germination occurrences of the Series 1 and Series 2 for each condition. Series2 started germination on Day 3 and finished on Day 8. Series1 started germination on Day 4 and finished on Day 10. Better germination rates were for Cdt2 and Cdt 4 regardless the series. Because of a higher temperature, Series 2 started to germinate sooner and terminated sooner as well. In terms of germination rates, the steep slope shows that they are higher for the Cdt 2 and Cdt 4 of Series 2 compared to the same conditions of Series1 with 2.75 and 1.9 against 1.1 and 1.0 germination per day respectively.

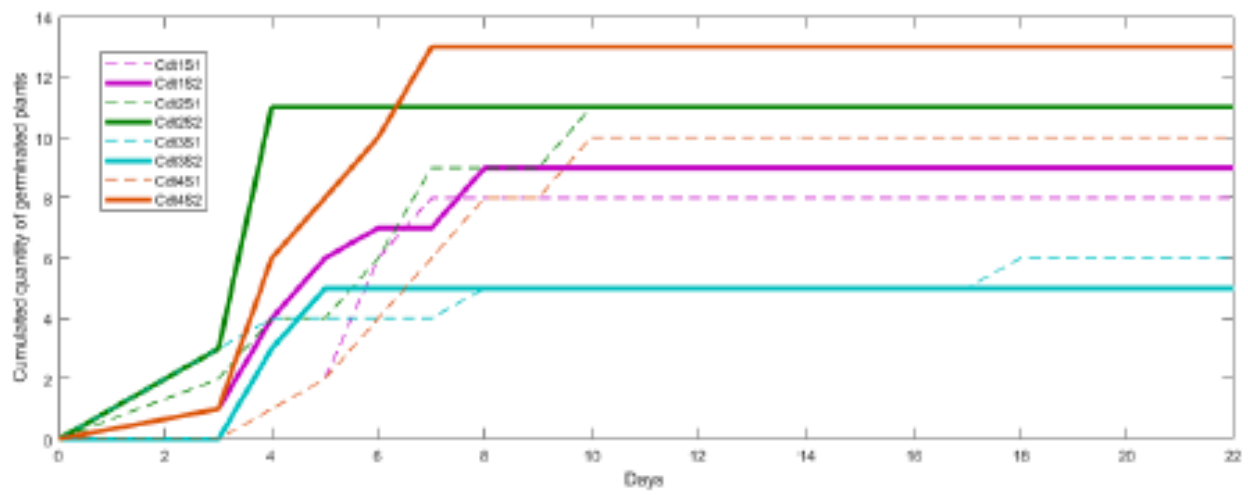

Figure 2: Germination occurrences of the Series1 (S1) and Series2 (S2) for each condition.

\subsubsection{General results}

After the appearance of the two cotyledons it takes a few days for the plant to initiate a small root system and produce the first real leaves. Figure 3 illustrate the quantity of plants with leaves and the mean quantity of leaves per plant as a function of days in the two series analyzed. It is on the 8th day that the first leaves appeared in our experimental device except for Cdt3 for which it occurred later. In the Series1, Cdt2 and Cdt4 gave the greatest quantities of plants, but Cdt1 and Cdt 2 produced the leafiest plants with a mean above 6 leaves per plants (SUPPL. 3, Figure 13). In the Series2, Cdt1 and Cdt2 both provide numbers of wellestablished plants with $45 \%$ to $50 \%$ germination, and here Cdt 2 produced the leafiest plants.
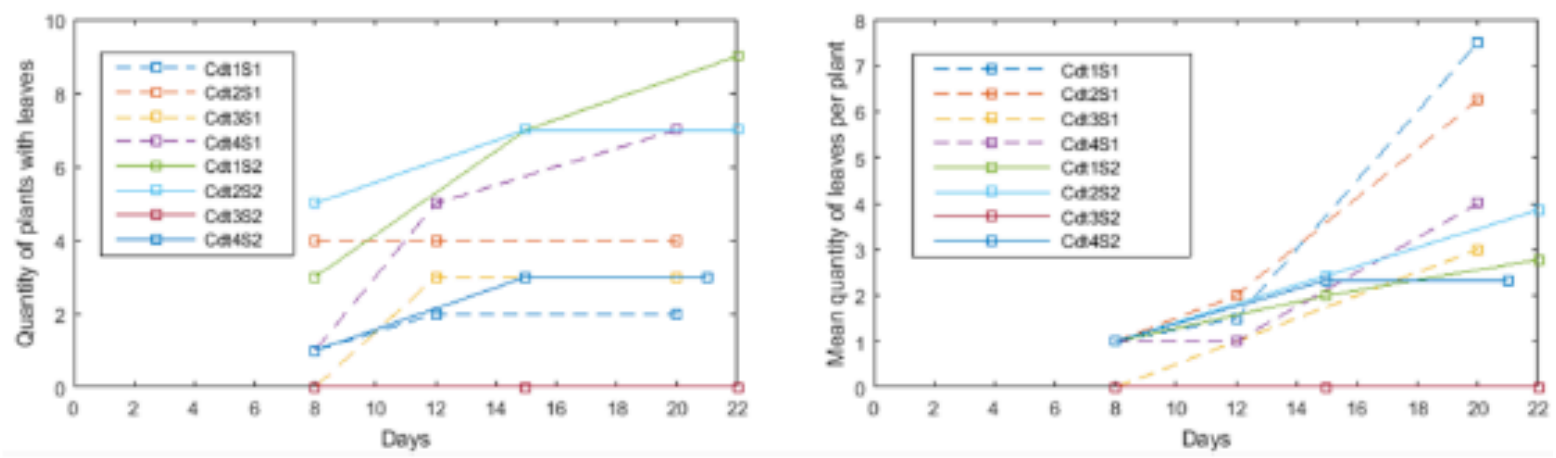

Figure 3: Quantity of plants with leaves (left) and mean quantity of leaves per plant (right) obtained for each condition tested and for the Series1 (S1) and Series2 (S2).

Due to its photoperiod which is identical to Cdt2, the results of fresh biomass of the experiment in the $2 U$ incubator are compared with those of climatic chambers. We observed that higher biomasses are obtained at the lowest temperatures (Table 5). Table 5 shows an inverse relation with the temperature between the ratio Fresh Weight Shoot/Fresh Weight Root and the mean fresh weight biomasses for Cdt2. This inter-series analysis is supported by 
2 tails t-test p-values that gave a great significant difference between the Cdt 2 of both series (Table 6). Cdt 2 and Cdt4 were almost equivalent in terms of FWB, but also FWS and FWR, with a ratio FWS/FWR of 0.46 for Cdt 2 and of 0.49 for Cdt4. T-tests with 2 tails assuming unequal variances between data of $\mathrm{Cdt} 2$ and $\mathrm{Cdt} 4$ gave p-values below 0.05 , indicating small significant differences between these groups.

Table 5: Illustration at different temperatures of the ratio FWS/FWR for the Cdt2 and Fresh Weight mean Biomasses per plant for each condition tested in the two series and in the $2 \mathrm{U}$ incubator.

\begin{tabular}{lccc}
\cline { 2 - 4 } Plant life before harvest & $22.5^{\circ} \mathrm{C}$ & $26^{\circ} \mathrm{C}$ & $29.5^{\circ} \mathrm{C}$ \\
\hline FWSFWR (Cdt2) & 1 month & 1.7 months & 1 month \\
\hline Mean FWB (mg) & 0.46 & 0.87 & 1.1 \\
& $858(\mathrm{Cdt1})$ & & $144(\mathrm{Cdt1})$ \\
& $455(\mathrm{Cdt} 2)$ & $222(2 \mathrm{U})$ & $174(\mathrm{Cdt} 2)$ \\
& $240(\mathrm{Cdt} 3)$ & & \\
& $304(\mathrm{Cdt} 4)$ & & \\
\hline
\end{tabular}

Table 6: 3 T-tests with 2 tails assuming unequal variances between FWB, FWR and FWS from Cdt2 for Series 1 and Series2 (S1, S2), Cdt2 and Cdt4 in S1, and Cdt1 and Cdt2 in S2 with alpha $=0.05$.

\begin{tabular}{lccc}
\hline p-value (2 tails) & Cdt2(S1, S2) & S1(Cdt2, Cdt4) & S2(Cdt1, Cdt2) \\
FWB & 0.001 & 0.027 & 0.616 \\
FWR & 0.0005 & 0.022 & 0.952 \\
FWS & 0.033 & 0.047 & 0.172 \\
\hline
\end{tabular}

The intra-series data analysis of Series 1 showed us that Cdt1 produced few plants which were the largest and gave a mean FWB double that of Cdt2 (Table 5). This Cdt1 had a root system of one plant equivalent to three of Cdt4 (SUPPL. 4, Figure 14).

\subsubsection{Statistics}

A principal component analysis was performed on plants functional traits measured from Series1 and Series2 for two reasons:

(a) Observe the location of functional traits variables relative to dimensions: We observed that all the variables are in the direction of dimension 1, except SSL and SL which explain the variability of the data in the direction of dimension 2. In Series 1 and Series2, BL is strongly correlated with the dimension 1 (SUPPL. 5, Table 10). In Series2 BL has a correlation coefficient of 0.95 with a p-values of $1.32 .10^{-7}$ indicating that this variable is significantly associated principal component 1 . The first 2 dimensions explained $93 \%$ and $88 \%$ of the data variance for Series1 and Series2 respectively (SUPPL. 5, Figure 15), and all the variables are well correlated with these dimensions (SUPPL. 5, Table 10) ${ }^{2}$. Therefore, dimensions greater than 2 will not be taken into account.

(b) Observe the distribution of groups of individuals from the conditions relatively to dimensions ${ }^{3}$ : Concerning the groups of individuals resulting from the conditions, we observed a different pattern depending on the series analyzed.

Series 1: Figure 4 biplot diagram clearly shows that the barycentre of each condition is located in a different quadrant: $\operatorname{Cdt} 1(+,-)$; $\operatorname{Cdt} 2(+,+)$; $\operatorname{Cdt} 3(-,+)$; Cdt4(-,-). The principal component 1 was strongly influenced by Cdt1 and Cdt 2 as their plant samples had the most positive scores among all conditions. Plants that have grown with $380 \mathrm{ppm} \mathrm{CO}_{2}$ have a

${ }^{2} \mathrm{R}$ software: dimdesc function in package FactoMineR.

${ }^{3} \mathrm{R}$ software: fviz_pca_biplot function in package factoextra. 
distribution organized symmetrically to those that have grown with $10000 \mathrm{ppm} \mathrm{CO}_{2}$ along the principal component 2 axis with respect to their photoperiod. This means that a high $\mathrm{CO}_{2}$ concentration will tend to decrease the plants fresh weight, number of leaves and total leaf surface area.

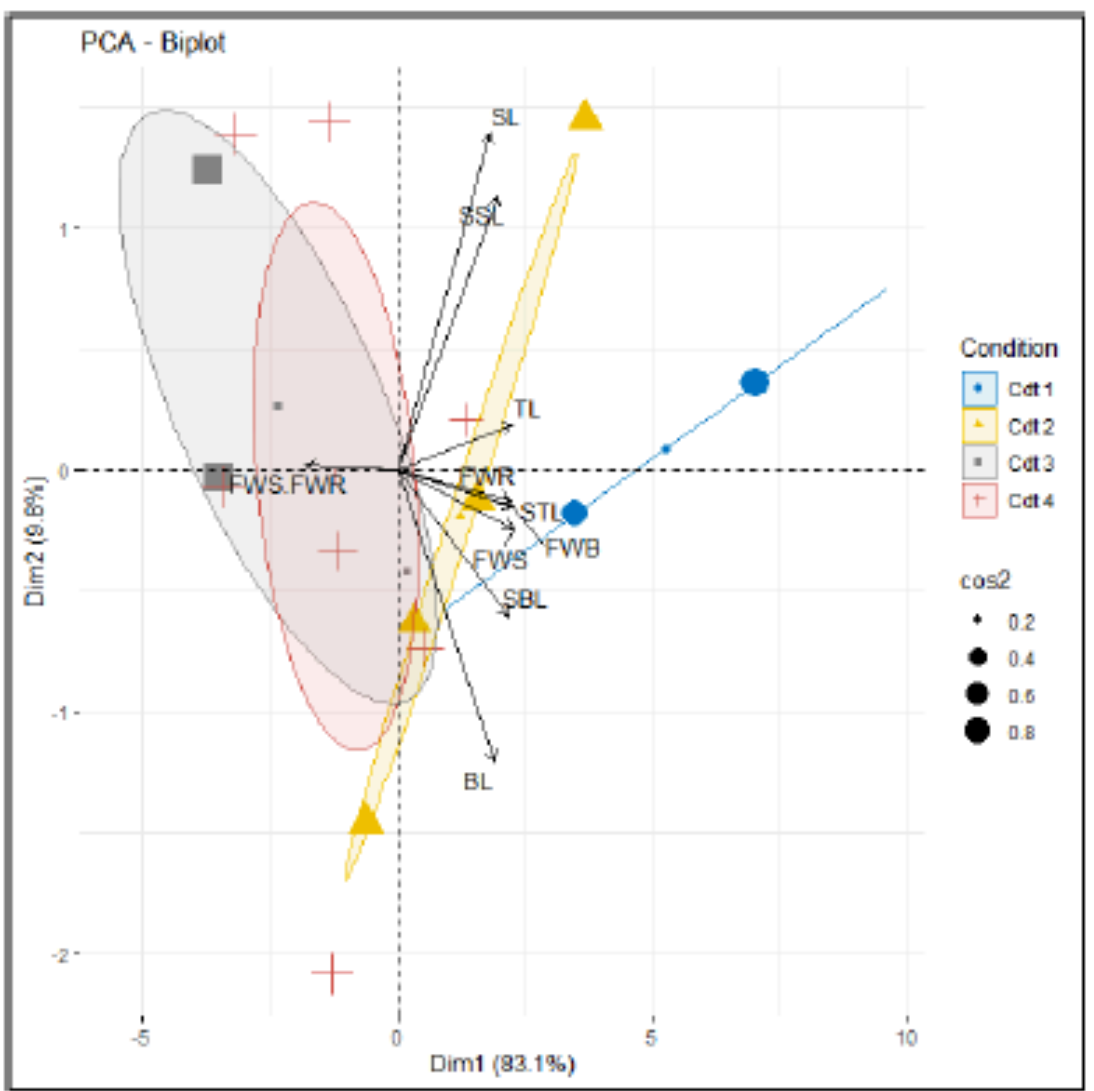

Figure 4: Biplots illustrating plant samples distribution per condition and a PCA for Series1 with elliptic confidence intervals drawn around the barycentre of each condition which is represented by a small point at the centre of the ellipse.

Series2: On Figure 5 biplot diagram, the ellipses location and plant sample distribution per condition cultivated at $29.5^{\circ} \mathrm{C}$ are quasi-identical, which is in accordance with t-test results for fresh weights that make no difference between Cdt2 and Cdt1 (Table 6). As shown in Table 10 (SUPPL. 5), in the Series 2 also, the dimension 2 is better correlated with variable SL and SSL. Therefore, a model should integrate variables related to the small leaves in order to consider the variability introduced by the dimension 2 . Finally, the use of these variables to explain the variability on principal component 2 is strengthen by their position on a diagram with dimensions 2 and 3 (SUPPL. 6, Figure 16c,f). 


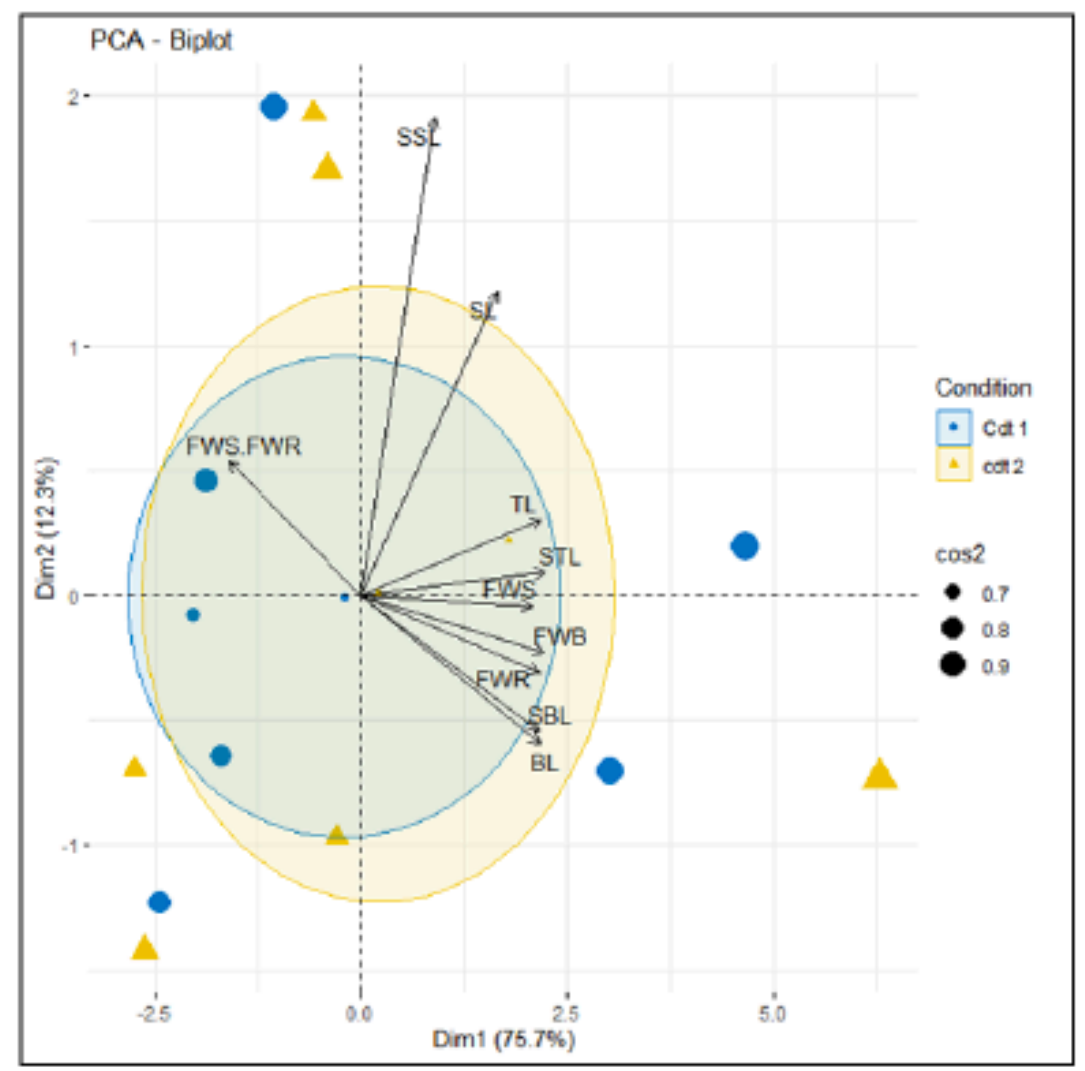

Figure 5: Biplots illustrating plant samples distribution per condition and a PCA for Series2 with elliptic confidence intervals drawn around the barycentre of each condition. Remark: due to technical problem with the incubator SCO40 in the second series we lost all the plants of Cdt3 at Day 10 and of Cdt4 at Day 22.

\subsection{The 2U incubator experiment}

In the near future, this biological experiment will be performed in space using a $3 \mathrm{U}$ CubeSat in which $2 \mathrm{U}$ will be used for the incubator. To achieve this, several adjustments are required in order to provide the plants with a suitable environment to live into the designed $2 \mathrm{U}$ incubator and some improvements are still under development. In particular, regarding preparation for qualification tests which will expose this payload to extremely harsh conditions such as vacuum, vibration or heat in order to assess the degassing potential and mechanical stability. To successfully pass those tests, the material used to build the incubator will be made of poly-aryl-ether-ether-ketone (PEEK), because it reduces degassing and heat conduction [13]. A first model based on finite element analysis using the methods Design Simulation and Pre-Post on the software Siemens NX Nastran allowed to generate possible scenario for the thermal stability of the incubator [5]. In addition, the two weak points which are the holes where the wires come out of the incubator and the door of the incubator will be sealed using hermetic wire feedthrough, screws and a lubricated double jointure system.

The future placement of the components of the incubator for microgravity should consider the difficulties that we faced and might integrate a few changes as it is presented in the Figure 6. A retractable bag should be used to avoid the need to fill the water tank with air to replace the liquid removed. The consequences will be to create a slight depression into the incubator and to help the pump pushing the nutrient solution through the tubes. The pump must be protected from the water condensation to avoid a short circuit or rust. The packsoil might go down to occupy the space where the pump was, therefore leaving more space for the plant to grow. A large panel of LEDs should be glued on the roof above the plants. The temperature and humidity sensor might be placed below the ethylene catalyst because its fan, which is used to 
agitated air into the incubator, blows directly on the flexible heater and could cause an error in the temperature estimation by the sensor. The camera viewing angle might also be changed to allow a simultaneous view of the leaves and the stems on the photos.

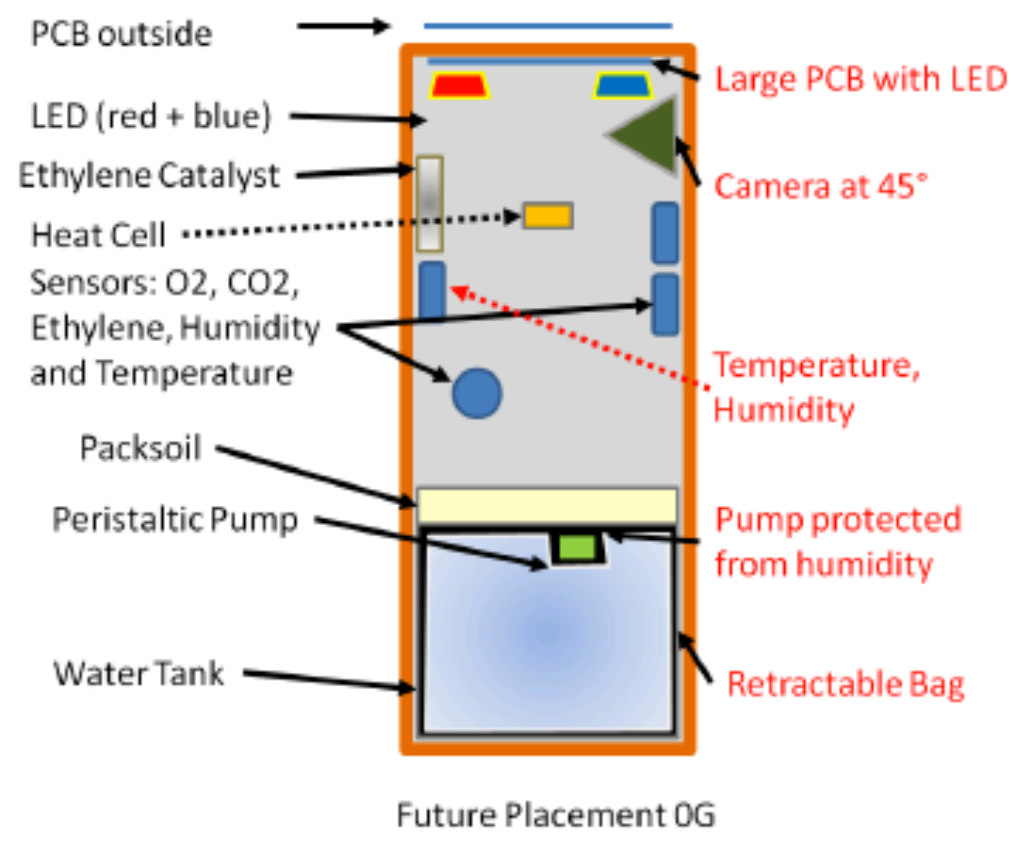

Figure 6: General illustration of the $2 \mathrm{U}$ incubator as it might be prototyped for the experiment under $0 \mathrm{G}$.

The PLA 3D printed prototype incubator succeeded in being waterproof and it was able to regulate well its internal temperature in a room with a stable external temperature at $23^{\circ} \mathrm{C}$. The silicon used to close the door and tiny holes made for the passage of wires allowed the maintenance of the internal humidity and prevented the system from microorganisms contamination. An Arduino Mega was able to control all the functions correctly, even though in its sequence of execution a delay due to daily watering decreased the day time of the photoperiod by up to 3.7 minutes without having any effect on the night period (SUPPL. 2, Table 9). The total energy consumption of the prototype could reach a maximum of $3 \mathrm{~W}$ when all the electronics were working. These electronics are the 8 LEDs, the pump, the heater, the sensors, the camera and the ethylene catalyst integrated to this prototype. The total mass of the incubator filled with nutrient solution and soil was $1.2 \mathrm{~kg}$, which is far below the $2 \mathrm{~kg}$ limitation required for this payload to be integrated into the CubeSat. Unfortunately, the camera's cables were malfunctioning, which is why no pictures are available. Photos taken with an onboard camera in such an incubator can help to follow the growing of the plants and also are a source of data. However, even without pictures showing the evolution stages of the plants, we evaluated them with some cautious hypotheses by interpreting gases fluctuations detected with the sensors.

\subsubsection{Sensors data}

The prime general observation of the $\mathrm{C}_{2} \mathrm{H}_{4}, \mathrm{CO}_{2}$ and $\mathrm{O}_{2}$ sensors graphs taken together (Figure $7 \mathrm{a}, \mathrm{b}, \mathrm{c})$ let us observe that three main events happened during the 62 days of cultivation into the incubator. The first event would be dated on the Day 7, the second appears to be ruling on an extended lapse of time going from Day 14 to Day 31 and the third appears to be starting on Day 50 and ending on Day 57. These 3 events can be attributable to the plants' metabolism; therefore we will name them physiological event 1,2 and 3 respectively. 

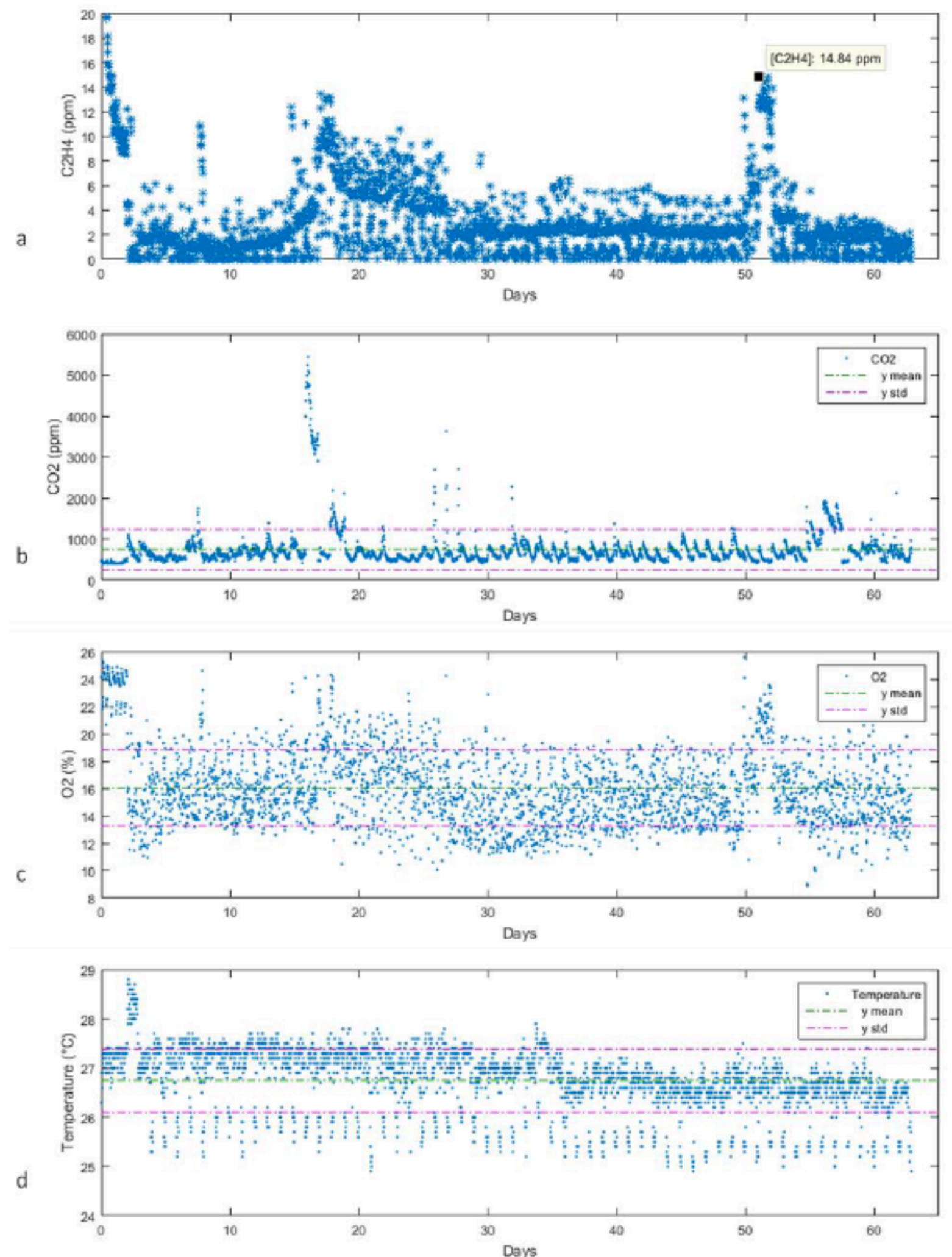

Figure 7: Graphs a,b,c,d respectively for ethylene, $\mathrm{CO}_{2}, \mathrm{O}_{2}$ and temperature as a function of time. 
Ethylene. The ethylene sensor indicated a high ethylene concentration of $33 \mathrm{ppm}$ at the beginning of the experiment. This high concentration was catalysed with the ethylene scrubber during the 3 first consecutive days until it reached $0 \mathrm{ppm}$ (Figure 8). At Day 0 the maximum temperature was $27.5^{\circ} \mathrm{C}$ and the rate catalysis was $0.03 \mathrm{ppm} / \mathrm{min}$ according to the 4th degree polynomial regression equation that fits this photocatalysis $y=2.6 \mathrm{e}^{-13 *} \mathrm{x}^{4}-3.6 \mathrm{e}^{-}$ ${ }^{9} \mathrm{x}^{3}+1.6 \mathrm{e}^{-5 *} \mathrm{x}^{2}-3.3 \mathrm{e}^{-2 *} \mathrm{x}+34$ (residuals $=11.898$ ). At Day 1 , the maximum temperature remained at $27.5^{\circ} \mathrm{C}$ and no further catalysis was observed. However, at the beginning of Day 2 , temperature rose up to $28.8^{\circ} \mathrm{C}$, so this additional energy allowed to perform the catalysis of the remaining $10 \mathrm{ppm}$ ethylene. The rate photocatalysis at this temperature was $0.05 \mathrm{ppm} / \mathrm{min}$ according to the equation $\mathrm{y}=8.9 \mathrm{e}^{-12 *} \mathrm{x}^{4}-1.4 \mathrm{e}^{-7 *} \mathrm{x}^{3}+8.3 \mathrm{e}^{-4 *} \mathrm{x}^{2}-2.2 * \mathrm{x}+2.1 \mathrm{e}^{+3}$ (residuals $=$ 8.1975).

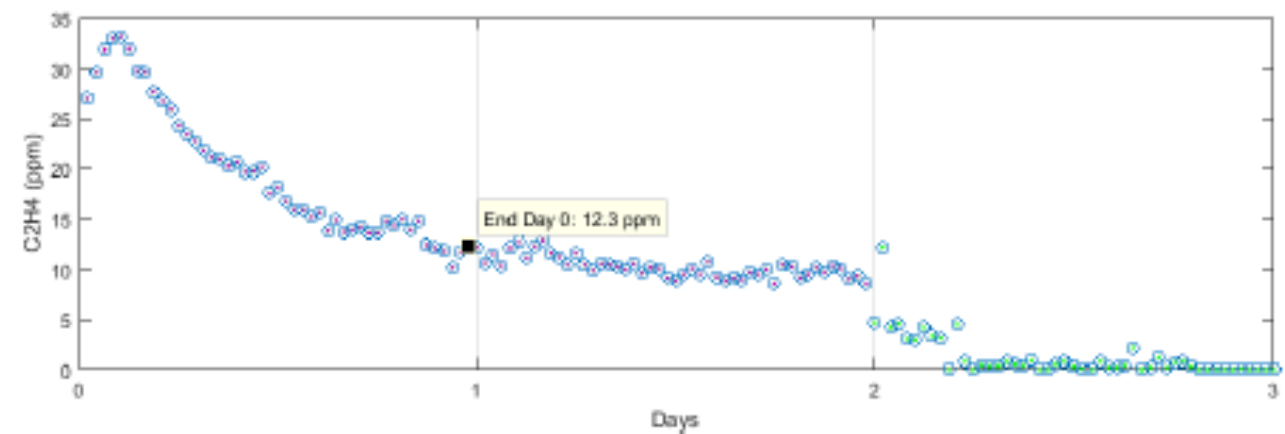

Figure 8: Photocatalytic degradation kinetics of ethylene. The vertical lines indicate the limits between Day 0, 1 and 2 during which the LEDs remained off.

Some variations in the ethylene production between the 4th and the 10th day and later from Day 14 to Day 31 are clearly attributable to a biological growing activity of the plantlets. According to the observation made in the PECC, the first peaks correspond to germination (Figure 2) and the second set of peaks correspond to the period when the big leaves are well developed with a start of smaller leaves that sprout below (Figure 3). As it can be seen on Figure $7 \mathrm{a}$, these two events are correlated with the rise of both $\mathrm{CO}_{2}$ and $\mathrm{O}_{2}$ indicating an increase in photosynthesis and respiration. Therefore, from these assumptions the hypothesis of a period of biomass production can effectively be validated. However, concerning the third event showing an increase of ethylene concentration up to $15 \mathrm{ppm}$ that started around the Day 49 , no correlation with $\mathrm{CO}_{2}$ was observable but only with $\mathrm{O}_{2}$ indicating that respiration rate did not rise proportionately to the photosynthesis rate. The subsequent decrease of $\mathrm{O}_{2}$ and rise of $\mathrm{CO}_{2}$ at Day 52 pinpoints an increase in respiration and not in photosynthesis. Therefore, the start of the senescence of the plants may have started at this moment and the third event might be an indicator of hydration stress. Indeed, we started the experiment with a tank full of nutrient solution, but the tube that dispenses water was torn which caused watering to interrupt. Some data collected is still significant after irrigation failure, probably on Day 49. For example, concerning the evolution of ethylene during a period of senescence, the data will serve as an indicator for the control programs which will be developed later. These programs will aim to prevent the system from an incident in the cultivation of plants in order to allow the implementation of corrective actions, such as the triggering of the ethylene catalyst, the reduction of luminosity or the change of photoperiod. However, the problem of interrupting the water supply due to torned tube will not exist in the system which will be operating in microgravity, because we will use a retractable bag that pushes the water into the pump.

Oxygen. $\mathrm{O}_{2}$ concentration remained quite stable during the whole experiment oscillating between $20 \%$ and $14 \%$ on a daily basis except during the 3 physiological events explained 
and at the beginning of the experiment. Simultaneously to the ethylene photocatalysis, we detected an $\mathrm{O}_{2}$ concentration that rose above $21 \%$ and remained above $24 \%$ during the 3 first days (Figure 7c). Under UV irradiation photocatalytic oxidation of water on $\mathrm{TiO}_{2}$ outputs as ultimate products $\mathrm{H}_{2}$ and $\mathrm{O}_{2}$ following the water splitting reaction $2 \mathrm{H}_{2} \mathrm{O}=\Rightarrow 2 \mathrm{H}_{2}+\mathrm{O}_{2}$ $[14,15]$. With $99 \%$ humidity, high $\mathrm{O}_{2}$ concentration could come from $\mathrm{H}_{2} \mathrm{O}$ photo-oxidation.

Carbon dioxide. The concentration of $10000 \mathrm{ppm} \mathrm{CO}_{2}$ initially placed into the incubator could not be maintained because $\mathrm{CO}_{2}$ equilibrated with the atmosphere concentration at $380 \mathrm{ppm}$ during the period of rise of dormancy, while the incubator was located in the refrigerator at $4^{\circ} \mathrm{C}$. Consequently, the $2 \mathrm{U}$ incubator experiment is almost similar to the Cdt 2 of the PECC but at $26^{\circ} \mathrm{C}$ and with a very high humidity ( $99 \%$ versus $72 \%$ maximum in the PECC).

$\mathrm{CO}_{2}$ concentration remained stable during the experiment oscillating between 380 and $1000 \mathrm{ppm}$ on a daily basis except during the 3 physiological events (Figure $7 \mathrm{~b}$ ).

Moreover, a closer look on a daily basis shows that $\mathrm{CO}_{2}$ assimilation fluctuates during the illumination period. The fluctuations are composed of periods of high respiration rate when just watered with the LEDs on, then the photosynthesis starts and is followed by photoinhibition after 12 hours during which period of respiration takes place until the next day. Two patterns of respiration rate were observed: a high respiration rate with a steep curve and a low respiration rate with a flat quasi horizontal curve (SUPPL. 7, Figure 17, Figure 18).

We observed a coincidence between the daily variation of $\mathrm{CO}_{2}$ and the decrease in the mean temperature from Day 36; however, the consequences of these observed fluctuations on plant development are unclear.

Temperature and humidity. Temperature and humidity remained globally stable during the 62 days of the experiment with a mean temperature of $26.7^{\circ} \mathrm{C}$ and a relative humidity at $99 \%$. The maximum daily temperature amplitude was $2.5^{\circ} \mathrm{C}$ going from $25^{\circ} \mathrm{C}$ to $27.5^{\circ} \mathrm{C}$ (Figure 7d). Temperatures below $26^{\circ} \mathrm{C}$ correspond to nighttimes temperatures obtained when all 8 LEDs are off. So for a period of 4 hours, the temperature oscillates between $25^{\circ} \mathrm{C}$ and the setting temperature which is $26^{\circ} \mathrm{C}$. Based on the Figure $7 \mathrm{~d}$, we observed at Day 36 a sudden and permanent temperature decrease of $0.5^{\circ} \mathrm{C}$ that allowed us to divide the experiment into two distinct phases. According to the PECC, mean FWB is between $455 \mathrm{mg}$ and $174 \mathrm{mg}$ after 30 days (Table 5). These amounts of biomass are very low and could not be sufficient to decrease the temperature inside the incubator. These variations could be attributable to the watering, but except for the Day 3 where the first watering started, we had no other correspondence between the watering schedule (SUPPL. 2, Table 9) and the occurrence of these temperature changes. However, the decrease of the daily mean temperature observed from Day 36 to Day 62 seems to be associated with the respiration patterns mentioned earlier (c.f. section 3.2.1, Carbon dioxide). Indeed, $84 \%$ of high respiration rate occurred between Day 7 and Day 35 when the mean temperature was $26.9^{\circ} \mathrm{C}$ and $71 \%$ of the low respiration rate were observable between Day 36 and Day 62 when the temperature was $26.4^{\circ} \mathrm{C}$. Besides, we saw that when the plants are just watered their respiration rate remains high for approximately 1 hour (SUPPL. 7, Figure 17). Therefore, the sudden temperature decrease together with the change for a low respiration rate on the same day could indicate the moment the membrane leakage became large enough to not be able to retain water. Consequently, the loss of water due to the leakage of the membrane might be responsible for the observed drop in temperature.

\subsubsection{Plants senescence}

After 62 days in the incubator, the two plants' development appeared to be similar regarding their number of leaves and height, but they had different weight. One was heavier with $249 \mathrm{mg}$ versus $194 \mathrm{mg}$ for the other one. Besides, it had a largest root system and contained less wilted 
leaves. When the incubator door is closed, the white walls of the prototype may have concentrated light and caused periods of photoinhibition. Indeed, most of its leaves were reddish indicating an accumulation of anthocyanin in the epidermis [16] generally found in young leaves to protect them from high energy light. Liakopoulos et al. demonstrated that anthocyanin in the leaves of Vitis vinifera decreased light reflectance between $500 \mathrm{~nm}$ and $630 \mathrm{~nm}$ and thus helped against photoinhibition [17]. More recently, a study of Melo et al. on Arabidopsis thaliana suggested that photosystem I (PSI) photoinhibition is not only a defence mechanism but it also prevents excessive reactive oxygen species (ROS) production, so it contributes to lessen oxidative stress. They concluded that the price to pay for this protection was a decrease in carbon assimilation used for normal growth of the plant [18].

The plants have suffered carbon losses due to an increased in respiration after Day 52, and to the production of a lot of ethylene. Considering only the carbon losses in the form of $\mathrm{C}_{2} \mathrm{H}_{4}$ reaching nearly $15 \mathrm{ppm}$ (Figure $7 \mathrm{a}$ ) and with an average biomass of $222 \mathrm{mg}$ per plant (Table 5), we can estimate that the plant has lost at least $3.33 \mathrm{mg}$ biomass during the 12 last days of the experiment. The PECC gave its best results in terms of biomass productivity with a light intensity of $570 \mu \mathrm{mol} . \mathrm{m}^{-2} \mathrm{~s}^{-1}$ and photoperiod of $20 \mathrm{~h} / 4 \mathrm{~h}$ for a period of 30 days at $22.5^{\circ} \mathrm{C}$ (Table 5). However, the $2 \mathrm{U}$ incubator showed that after 62 days all the plants were reddish (SUPPL. 8, Figure 19), senescent and their biomass remained the same as a 30 days old plant that would have grown at $26^{\circ} \mathrm{C}$ in a climatic chamber. Taken together, these facts tend to indicate that the plants suffered from oxidative stress due to an excess of light energy over a long period of time which, combined with the drought of the last week of experience, accelerated their senescence.

\subsection{Model}

The model built is based on the determination of FWB, because this variable allows us to determine other plants functional traits variables with a very good approximation. A correlation coefficient matrix shows $\mathrm{R}^{2}$ values between the variables, and it can be seen that once FWB is determined, it becomes easier to estimate the rest of the values of the functional traits (SUPPL. 8, Table 11). However, in order to determine the FWB value, we had to consider a set of variables which led to the formulation of 1st and 2nd order multivariate polynomial equations. To do this, we used all the data from Series 2 , as conditions 1 and 2 were proven not to be significantly different (Table 6 and Figure 5). A maximum of 5 easily visible and measurable variables were used in the model: the quantity of big leaves, the length of the leaflets of the big leaves and of the small leaves, to which we added the quantity of small leaves and the surface area of the small leaves because these last two variables have the highest contribution on the principal component 2 (Figure 5). The determined polynomial equations are summarized in Table 7.

Table 7: Top 6 equations that minimizes the error calculated with experimental data from the design of experiment and from the $2 \mathrm{U}$ incubator experiment to get FWB.

\begin{tabular}{llcc}
\hline & & RMSPE & RMSPE \\
Eq. & Equations & PECC & 2U \\
(1) & $95.88 * \mathrm{BL}+10.91 * \mathrm{SL}-0.99 * \mathrm{BFOL}+22.38 * \mathrm{SFOL}-30.1$ & 0.19 & 0.08 \\
$(2)$ & $94.06 * \mathrm{BL}-0.68 * \mathrm{SL}+0.6 * \mathrm{SSL}+52.48$ & 0.17 & 0.08 \\
$(3)$ & $-44.22 * \mathrm{BFOL}+178.53 * \mathrm{SFOL}+8.31 * \mathrm{BFOL}^{2}-19.47 * \mathrm{SFOL}^{2}-294.57$ & 0.18 & 1.22 \\
$(4)$ & $95.36 * \mathrm{BL}-0.75 * \mathrm{SL}+0.23 * \mathrm{SSL}+0.002 * \mathrm{SSL}^{2}+64.97$ & 0.15 & 0.08 \\
$(5)$ & $-39.82 * \mathrm{BFOL}+196.01 * \mathrm{SFOL}+7.63 * \mathrm{BFOL}^{2}-23.65 * \mathrm{SFOL}^{2}+0.44 * \mathrm{SSL}-323.58$ & 0.17 & 1.18 \\
\hline \multicolumn{3}{c}{$*$ For a best fit, all equations were divided by 3.548 when applied on 2U incubator. }
\end{tabular}

After having determined FWB, we calculated other functional traits values with the equations given in Table 8, where the total leaf surface area was obtained using FWB value. In order to 
obtain the surface area of small leaves, the surface area of big leaves is determined using Equation 9 and its value is subtracted from the total surface area of the leaves.

Table 8: Equations and correlation coefficient between various variables to determine STL, SBL and SSL.

\begin{tabular}{lll} 
Eq. & Equations & $\mathbf{R}^{2}$ \\
$(6)$ & FWR $=0.6776 * \mathrm{FWB}-29.833$ & 0.98 \\
(7) & $\mathrm{STL}=1.0038 * \mathrm{FWB}-21.799$ & 0.95 \\
$(8)$ & $\mathrm{STL}=101.96 * \mathrm{BL}+72.293$ & 0.94 \\
$(9)$ & $\mathrm{SBL}=0.9698 * \mathrm{STL}-80.513$ & 0.95 \\
$(10)$ & FWS $=$ FWB - FWR & n.a. \\
(11) & SSL $=$ STL - SBL & n.a. \\
\hline
\end{tabular}

\subsubsection{Model results applied in PECC Series 1 and on the 2U incubator experiment}

Two calculations path were carried out to evaluate the model by estimating FWB, FWR, FWS, STL, SBL and SSL. The first path used Equation 1, 6, 10, 7, 9, 11 and the second used Equation 4, 6, 10, 7, 9, 11. Equation 4 gave the least error for both experiment types (Table 7). Nonetheless, Equation 1 was primarily used because it does not contain the variable SSL. Indeed, SSL is not easy to determine when plants have big leaves, because the camera cannot take a photo of all the small leaves growing under the bigger ones. The two paths are illustrated in SUPPL. 9, Figure 20. In this figure, the quantity of values per condition corresponds to the number of living individuals counted at the end of the experiment.

Afterwards, each estimated result was subtracted from the corresponding measured value giving a new value that we named Delta. Delta from the first and second calculation path are $D_{\text {I }}$ and $D_{\text {II }}$ respectively. The absolute value of $D_{\text {I }}$ and $D_{\text {II }}$ are subtracted to give Delta_Val_Abs, which is positive if the first path is closer to the measured value, negative if the second path is closer to the measured value or close to zero if both paths are equivalent.

The graphs in Figure 9 summarize the main model results for the PECC (Series1) and 2U incubator experiments. These graphs are based on some of the data sets provided in Supplemental Data (SUPPL. 9, Figure 20).

Fresh Weight Biomass: Overall, FWB was estimated very well by the model for plants weighing less than $500 \mathrm{mg}$ (Figure 9a). The estimates for the plants in the $2 \mathrm{U}$ incubator did not differ significantly from the measured values. In Series1, FWB was underestimated, but better estimated using Equation 4 . In the $2 \mathrm{U}$ incubator, FWB was accurately estimated within $3 \mathrm{mg}$ for one out of two plants.

Fresh Weight Roots: In Series1, FWR was slightly overestimated with the two calculations path by approximately $35 \mathrm{mg}$ for low roots mass $(<300 \mathrm{mg})$. In the $2 \mathrm{U}$ incubator, FWR was accurately estimated within $2.8 \mathrm{mg}$ for one out of two plants (Figure $9 \mathrm{~b}$ ).

It should be noted that the model greatly underestimated the FWR for root systems weighing more than $380 \mathrm{mg}$ like those of Cdt1 and for a plant of Cdt2. In fact, all other values of calculated variables diverge considerably from the values measured when the root mass weighs more than $300 \mathrm{mg}$.

Fresh Weight Shoot: In Series1, FWS was overestimated by approximately $25 \mathrm{mg}$ in both calculation path because FWB and FWR were underestimated. In the 2U incubator, FWS was accurately estimated within $5.9 \mathrm{mg}$ for one out of two plants (Figure 9c).

Surface area of Small Leaves: In Series1, SSL values were not well estimated by the model, except in a short range where there is convergence between $75 \mathrm{~mm}^{2}$ and $100 \mathrm{~mm}^{2}$ (Figure 9d). In the 2U incubator, Delta_Val_Abs gave values close to zero for SSL, which means that the values obtained were almost identical using the two calculation paths.

Total Surface area of Leaves and Surface area of Big Leaves: In Series1, except for the plants of Cdt1 and for the two biggest plants of Cdt2, STL and SBL were accurately estimated 
(Figure 9e,f). In the $2 \mathrm{U}$ incubator, both $\mathrm{D}_{\mathrm{I}}$ and $\mathrm{D}_{\text {II }}$ gave positive $\mathrm{STL}$ and $\mathrm{SBL}$ values. The model slightly underestimated these variables by approximately $10 \%$ and $13 \%$ successively for STL and SBL.

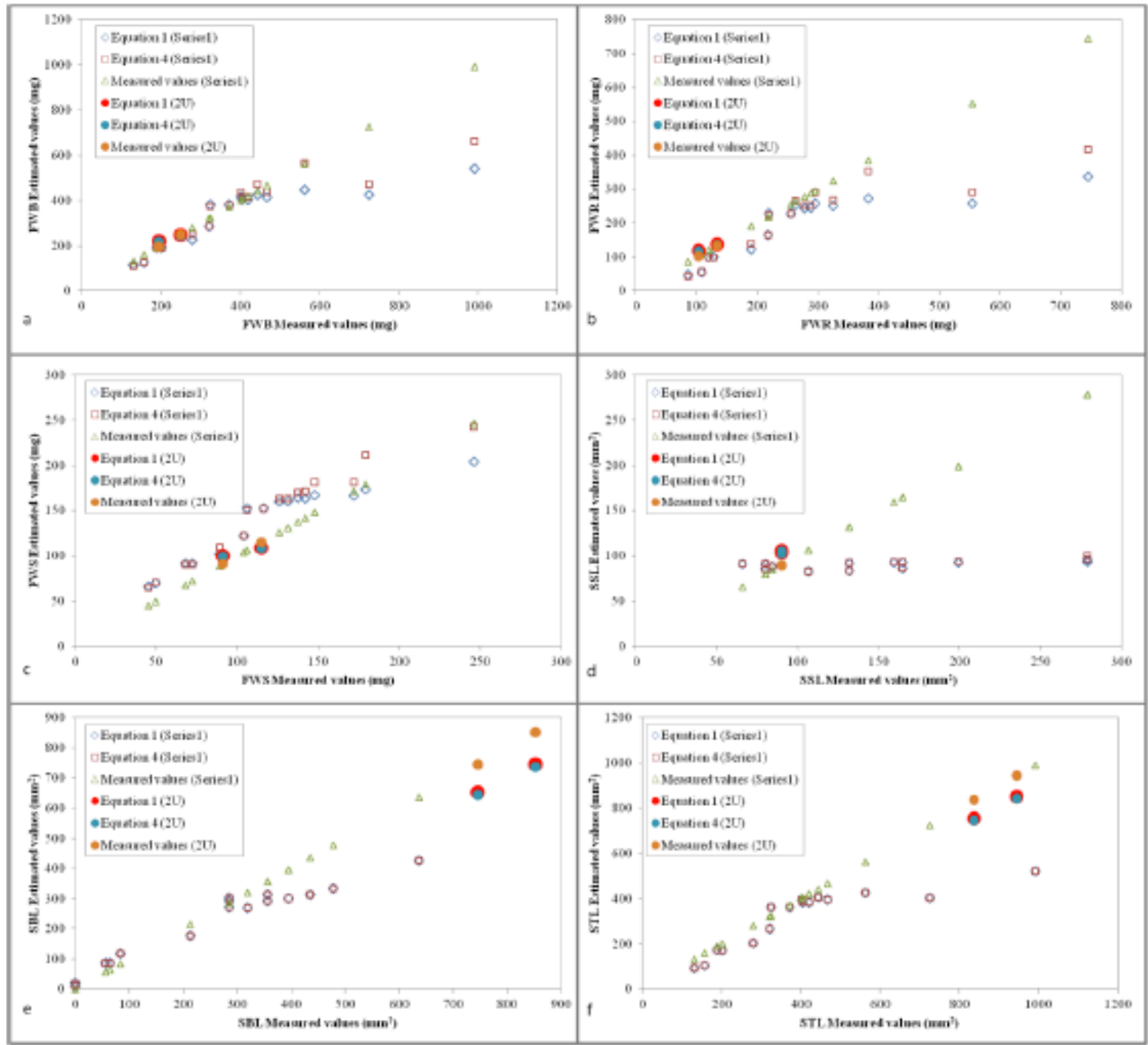

Figure 9: Model results for FWB, FWR, FWS and SSL from the PECC (Series1) and 2U incubator experiments.

\section{Conclusion}

We built a $2 \mathrm{U}$ prototype incubator to perform the germination and growing of the model leguminous species Medicago truncatula under a controlled environment that worked for 62 days. This prototype incubator was able to work with a minimal energy consumption (less than 4 Watt), it had a total weight below $1.5 \mathrm{~kg}$ and was able to remove plants ethylene production thanks to its ethylene scrubber that performs its catalysis with UV light on a $\mathrm{TiO}_{2}$ coated plexiglass. We demonstrated that scarified seeds gave the best germination rate in about 7 days after the rise of dormancy.

The $2 \mathrm{U}$ incubator experiment allowed the germination and growth of 2 big plants for approximately 52 days. The incubator was able to maintain a relatively stable temperature throughout the experiment. With the same light intensity, but without a short circuit in the watering, the plant experiment in climatic chambers produced plants of biomass equivalent to 
those that grew in the $2 \mathrm{U}$ incubator. Light measurement in the closed incubator should be done to suit the needs of the plants. The packsoil supported well the soil but the membrane was drilled by the root systems which led to their expansion out of the packsoil. The design of experiment realised in plant climatic chambers helped us to choose apparently good conditions to be used in the $2 \mathrm{U}$ incubator $\left(26^{\circ} \mathrm{C}, 380 \mathrm{ppm} \mathrm{CO}_{2}\right.$ and $20 \mathrm{~h} / 4 \mathrm{~h}$ photoperiod). However, after 49 days, the plants faced daily photoinhibition with severe hydration stress; thus, it started an accelerated senescence. The plant experiment in climatic chambers allowed us to build a model based on the knowledge acquired on the expression of the variability of plant functional traits in this device. This model gave us very good estimates of fresh biomasses and fairly good estimates of total surface area as well as surface area of big leaves. However, the estimation of the surface area of small leaves needs to be improved.

In the future, the placement of components must be optimized for better operation of the sensors and better management of the space available for plant growth.

\section{Acknowledgments}

The research on the Spacebean project was founded by the Canadian Space Agency. All the research was performed at Ecole Polytechnique de Montreal with members of the technical society PolyOrbite. No competing financial interests exist.

\section{References}

[1] S.S. Guo, R.X. Mao, L.L. Zhang, Y.K. Tang, Y.H. Li, Progress and prospect of research on controlled ecological life support technique, Reach. 6 (2017) 1-10. https://doi.org/10.1016/j.reach.2017.06.002.

[2] P. Zabel, M. Bamsey, D. Schubert, M. Tajmar, Review and analysis of over 40 years of space plant growth systems, Life Sci. Sp. Res. 10 (2016) 1-16.

https://doi.org/10.1016/j.1ssr.2016.06.004.

[3] R.J. Rose, Medicago truncatula as a model for understanding plant interactions with other organisms, plant development and stress biology: Past, present and future, Funct. Plant Biol. 35 (2008) 253-264. https://doi.org/10.1071/FP07297.

[4] T. Huguet, J.M. Prosperi, Medicago truncatula : a legume model-plant. The Genus Medicago in the Mediterranean region: Current situation and prospects in research., in: CIHEAM. 18 171-175, 1996.

[5] G. Rodriguez, Rapport de fin de session, 2018. https://github.com/ctrouillefou/Spacebean_Docs/blob/master/MEC6901 - Rapport de fin de session - Gabriel Rodriguez.pdf.

[6] W. Zhou, S.J. Durst, M. Demars, B. Stankovic, B.M. Link, G. Tellez, R.A. Meyers, P.W. Sandstrom, J.R. Abba, Performance of the Advanced ASTROCULTURE TM Plant Growth Unit During ISS-6A / 7A Mission, (2002).

[7] A. Galarneau, A. Sachse, B. Said, C.H. Pelisson, P. Boscaro, N. Brun, L. Courtheoux, N. Olivi-Tran, B. Coasne, F. Fajula, Hierarchical porous silica monoliths: A novel class of microreactors for process intensification in catalysis and adsorption, Comptes Rendus Chim. 19 (2016) 231-247. https://doi.org/10.1016/j.crci.2015.05.017.

[8] A. Galarneau, Z. Abid, B. Said, Y. Didi, K. Szymanska, A. Jarzebski, F. Tancret, H. Hamaizi, A. Bengueddach, F. Di Renzo, F. Fajula, Synthesis and textural characterization of mesoporous and meso-/macroporous silica monoliths obtained by spinodal decomposition, Inorganics. 4 (2016).

https://doi.org/10.3390/inorganics4020009. 
[9] Magnitude.io, ExoLab-8, (n.d.). https://magnitude.io/exolab-8/ (accessed October 18, 2020).

[10] J. Schulze, J.J. Drevon, P-deficiency increases the O2 uptake per N2 reduced in alfalfa, J. Exp. Bot. 56 (2005) 1779-1784. https://doi.org/10.1093/jxb/eri166.

[11] J. Schulze, M.A.N. Mohamed, G. Carlsson, J.J. Drevon, Phosphorous deficiency decreases nitrogenase activity but increases proton efflux in N 2-fixing Medicago truncatula, Plant Physiol. Biochem. 49 (2011) 458-460.

https://doi.org/10.1016/j.plaphy.2011.01.022.

[12] G.W. Stutte, M.S. Roberts, Microgravity effects on the early events of biological nitrogen fixation in medicago truncatula: Results from the synrge experiment, Eur. Sp. Agency, (Special Publ. ESA SP. 706 SP (2013).

[13] D.J.Y.S. Pagé, Neutron And Gamma Radiation Effects On The Viscoelastic Behaviour of PEEK, 1997. https://doi.org/10.1017/S0266078400009482.

[14] R. Li, Y. Weng, X. Zhou, X. Wang, Y. Mi, R. Chong, H. Han, C. Li, Achieving overall water splitting using titanium dioxide-based photocatalysts of different phases, Energy Environ. Sci. 8 (2015) 2377-2382. https://doi.org/10.1039/c5ee01398d.

[15] T. Jafari, E. Moharreri, A.S. Amin, R. Miao, W. Song, S.L. Suib, Photocatalytic water splitting - The untamed dream: A review of recent advances, Molecules. 21 (2016). https://doi.org/10.3390/molecules21070900.

[16] M. Juvany, M. Müller, S. Munné-Bosch, Photo-oxidative stress in emerging and senescing leaves: A mirror image, J. Exp. Bot. 64 (2013) 3087-3098. https://doi.org/10.1093/jxb/ert174.

[17] G. Liakopoulos, D. Nikolopoulos, A. Klouvatou, K.A. Vekkos, Y. Manetas, G. Karabourniotis, The photoprotective role of epidermal anthocyanins and surface pubescence in young leaves of grapevine (Vitis vinifera), Ann. Bot. 98 (2006) 257-265. https://doi.org/10.1093/aob/mc1097.

[18] Y. Lima-Melo, V.T.C.B. Alencar, A.K.M. Lobo, R.H.V. Sousa, M. Tikkanen, E.M. Aro, J.A.G. Silveira, P.J. Gollan, Photoinhibition of photosystem i provides oxidative protection during imbalanced photosynthetic electron transport in Arabidopsis thaliana, Front. Plant Sci. 10 (2019) 1-13. https://doi.org/10.3389/fpls.2019.00916. 


\section{Supplementary data}

SUPPL. 1

- Big leaves versus small leaves justification:
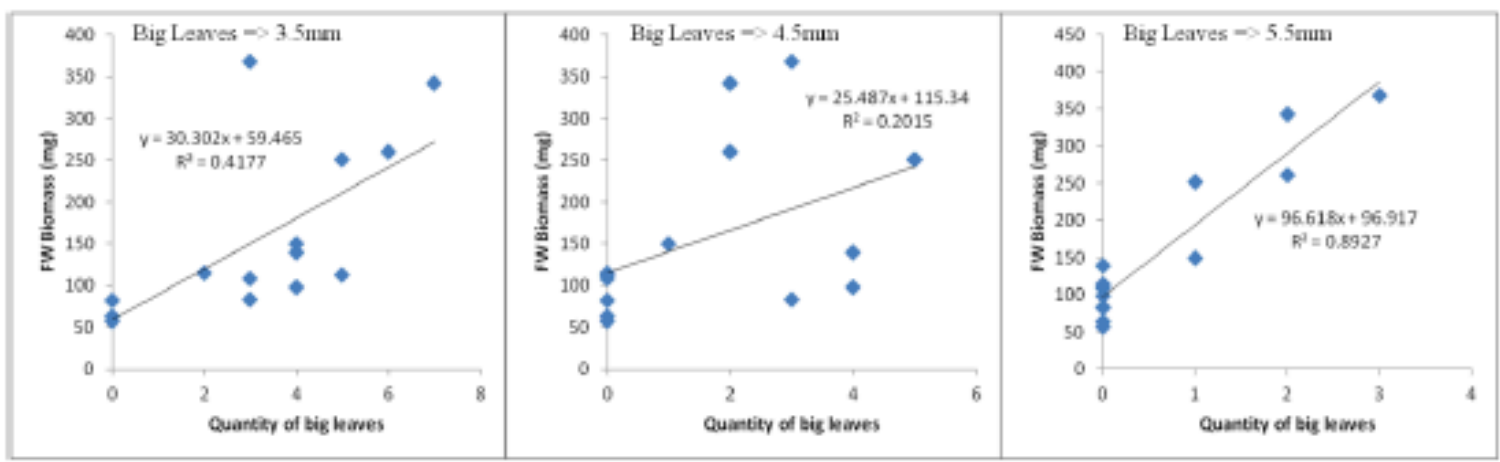

Figure 10: Relation between FWB and the quantity of big leaves of $3.5,4.5$ and $5.5 \mathrm{~mm}$ length.

The 3 graphics represent FWB as a function of quantity of leaves. The relation between FWB and the quantity of leaves become well correlated when the size of longest leaflet reaches $5.5 \mathrm{~mm}$. Hence, the big leaves were established as such the leaves with the longest leaflet is above $5.5 \mathrm{~mm}$.

\section{- Determination of Leaf Area:}
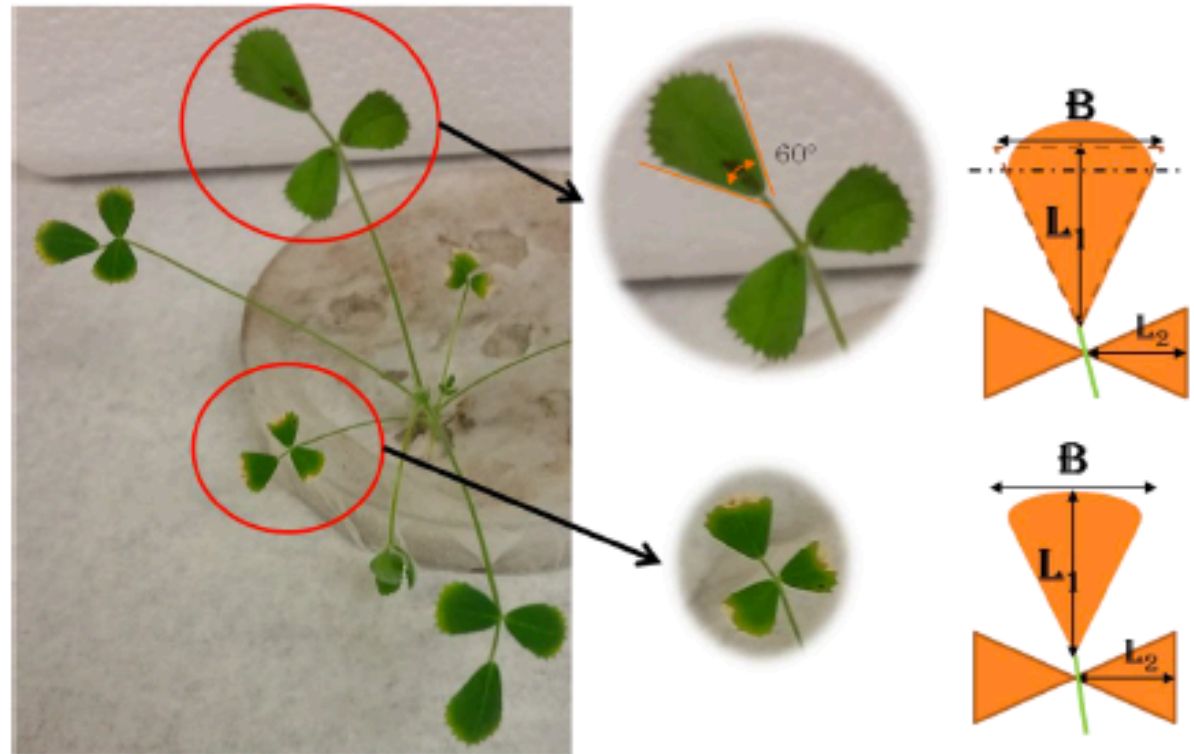

Figure 11: Illustration of the parameters used to determine the surface area equation of the leaves.

$\mathrm{B}$ is the width of the leaflet, and $b$ is half the width of the leaflet. $b=\tan \left(30^{\circ}\right) L$

The surface area of a leaflet is :

The surface area of the big leaflet is ( $\mathrm{S}_{\mathrm{b}}$ leaflet):

The surface area of the 2 small leaflets is ( $\left.\mathrm{S}_{\mathrm{s}_{-} \text {leaflets }}\right)$ :
$S_{\text {leaflet }}=b L$

$S_{b_{-} \text {leaflet }}=\tan \left(30^{\circ}\right) L_{1}^{2}$

$S_{s_{-} \text {leaflets }}=2 \tan \left(30^{\circ}\right) L_{2}^{2}$

Therefore, the surface area of a leaf is $\left(\mathrm{S}_{\text {leaf }}\right)$ :

$S_{\text {leaf }}=S_{b_{-} \text {leaflet }}+S_{s_{-} \text {leaflets }}=\tan \left(30^{\circ}\right) L_{1}^{2}+2 \tan \left(30^{\circ}\right) L_{2}^{2}$ 
The ratio $L_{1} / L_{2}$ is equal to 1.25 and 1.36 for big and small leaves successively. Hence, we can determine $L_{2}$ from $L_{1}$ such that $L_{2}=L_{1} /\left(L_{1} / L_{2}\right)$ and rewrite the $S_{\text {leaf }}$ expression.

The surface area of a leaf will be determined as follows:

- For a big leaf: $\quad S_{\text {Big_leaf }}=\tan \left(30^{\circ}\right) L_{1}^{2}+2 \tan \left(30^{\circ}\right)\left(L_{1} / 1.25\right)^{2}$

$S_{\text {Big_leaf }}=\tan \left(30^{\circ}\right) L_{1}^{2}\left(1+2 / 1.25^{2}\right)$

$S_{\text {Big_leaf }}=\tan \left(30^{\circ}\right) L_{1}^{2} * 2.28$

- For a small leaf: $\quad S_{\text {Small_leaf }}=\tan \left(30^{\circ}\right) L_{1}^{2}+2 \tan \left(30^{\circ}\right)\left(L_{1} / 1.36\right)^{2}$

$S_{\text {Small_leaf }}=\tan \left(30^{\circ}\right) L_{1}^{2}\left(1+2 / 1.36^{2}\right)$

$S_{\text {Small_leaf }}=\tan \left(30^{\circ}\right) L_{1}^{2} * 2.08$ 
This is the calendar proposed for watering during the 14 weeks of the experimentation in microgravity. In the present case, the experiment lasted 9 weeks.

Table 9: Calendar followed for plants daily watering.

\begin{tabular}{lccc}
\hline \multicolumn{1}{c}{ Time } & Weeks & $\begin{array}{c}\text { Daily } \\
\text { Watering } \\
\text { (ml/d) }\end{array}$ & $\begin{array}{c}\text { Watering } \\
\text { Time } \\
\text { (min) }\end{array}$ \\
Day 0 to Day 2 & 1 & 0 & 0 \\
Day 3 to Day 6 & 1 & $1.5^{*}$ & 1.4 \\
Day 7 to Day 13 & 2 & 2 & 1.9 \\
Day 14 to Day 20 & 3 & 2 & 1.9 \\
Day 21 to Day 27 & 4 & 3 & 2.8 \\
Day 28 to Day 34 & 5 & 3 & 2.8 \\
Day 35 to Day 41 & 6 & 3 & 2.8 \\
Day 42 to Day 48 & 7 & 3 & 2.8 \\
Day 49 to Day 55 & 8 & 4 & 3.7 \\
Day 56 to Day 62 & 9 & 4 & 3.7 \\
Day 63 to Day 69 & 10 & 4 & 3.7 \\
Day 70 to Day 76 & 11 & 4 & 3.7 \\
Day 77 to Day 83 & 12 & 5 & 4.6 \\
Day 84 to Day 90 & 13 & 5 & 4.6 \\
Day 91 to Day 97 & 14 & & \\
\hline
\end{tabular}
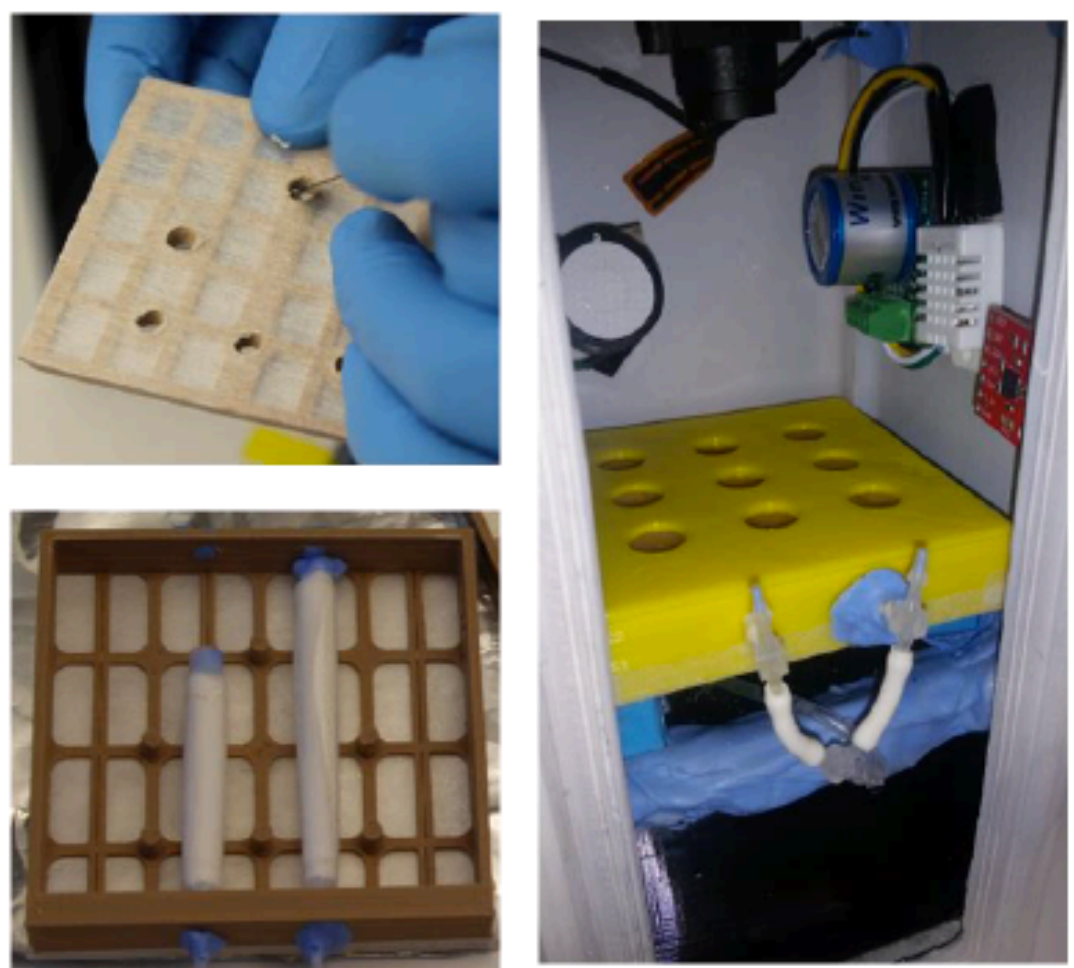

Figure 12: Old Packsoil version with membranes seed supports (left), and its new version built waterproof PLA without membrane (right). It is equipped with a support for the monoliths. 
SUPPL. 3
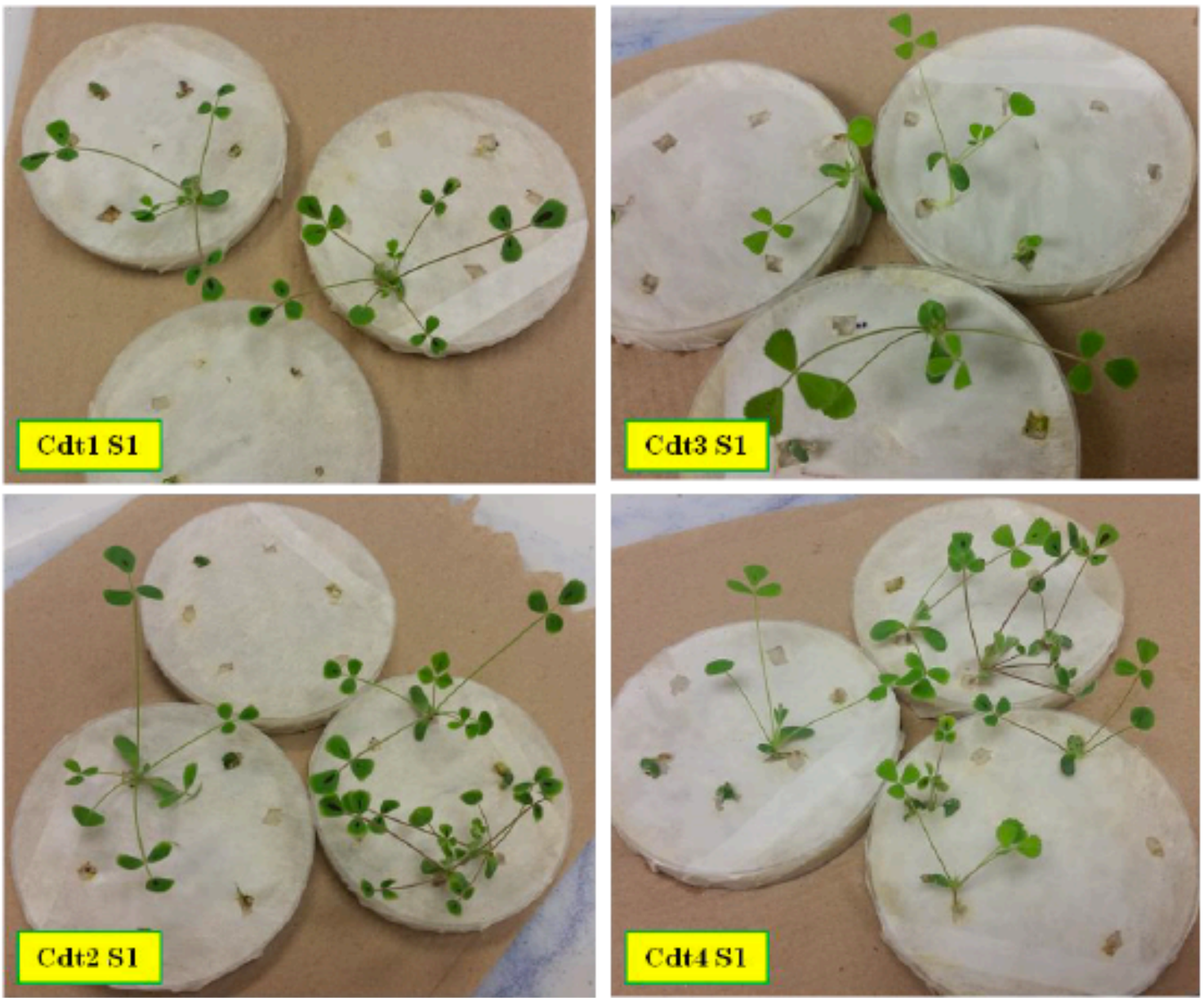

Figure 13: Plants after 4 weeks cultivation for the Series1. 

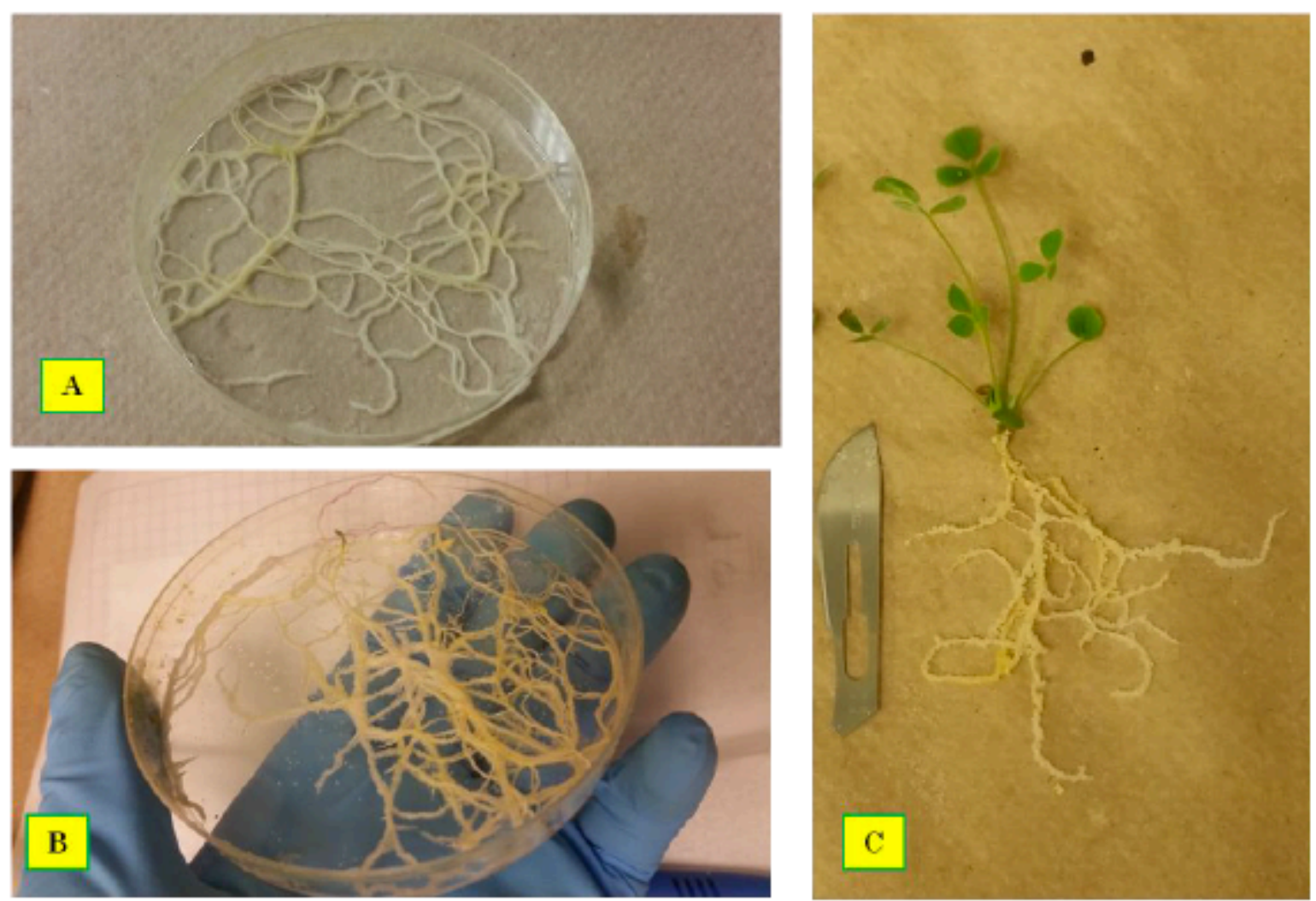

Figure 14: Biomass produced by the root systems of condition 1 versus condition 4 in the Series 1.

A: Root development of 1 plant in Cdt1.

B: Roots development of 3 plants in Cdt4.

C: In Cdt4, root length versus leaves length, with FWS/FWR $=0.49$. A noticeable particularity is the leaves that start directly at the collar for the Cdt4. This trait is confirmed by the heights between the root system and the location origin of leaves when comparing Cdt 2 and Cdt4 $(1.4 \mathrm{~cm}$ and $0.5 \mathrm{~cm}$ respectively). This particularity makes plants of Cdt4 appear more compact. The hypothesis of a consequence of the gas composition is plausible, as $\mathrm{CO}_{2}$ concentration is the unique difference between these conditions tested. 


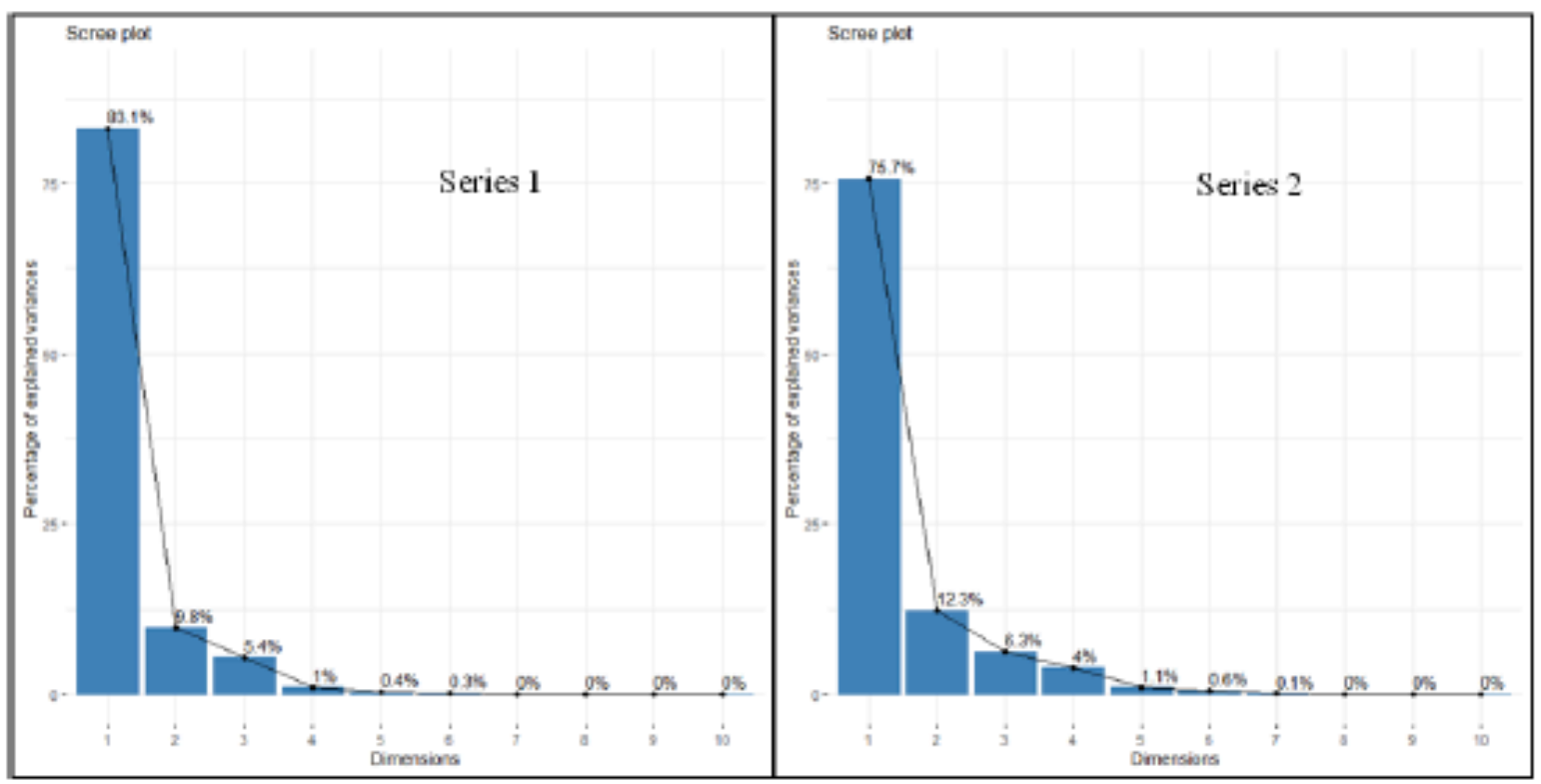

Figure 15: Eigenvalues obtained to measure the amount of variance explained for each principal component.

Table 10: Correlations and p-values obtained to identify the variables most significantly associated with a given principal component (Dimension).

\begin{tabular}{|c|c|c|c|c|}
\hline & & variable & correlation & p.value \\
\hline \multirow[t]{12}{*}{ Series 1} & \multirow[t]{10}{*}{ Dim. 1} & STL & 0.9861981 & $2.47 \mathrm{E}-12$ \\
\hline & & FWS & 0.9859094 & $2.85 \mathrm{E}-12$ \\
\hline & & FWB & 0.9762276 & $1.08 \mathrm{E}-10$ \\
\hline & & $\mathrm{TL}$ & 0.9752208 & $1.44 \mathrm{E} \cdot 10$ \\
\hline & & FWR & 0.9623302 & $2.61 \mathrm{E}-09$ \\
\hline & & $\mathrm{SBL}$ & 0.9522 & $1,35 \mathrm{E}-08$ \\
\hline & & SSL & 0.8491495 & $3.17 \mathrm{E}-05$ \\
\hline & & $B L$ & 0.8202044 & $9.98 \mathrm{E} \cdot 05$ \\
\hline & & SL & 0.7836109 & $3.29 \mathrm{E}-04$ \\
\hline & & FWS FWR & -0.785864 & $3.08 \mathrm{E} \cdot 04$ \\
\hline & \multirow[t]{2}{*}{ Dim. 2} & SL & 0.6041409 & $1.32 \mathrm{E}-02$ \\
\hline & & $\mathrm{BL}$ & -0.5212198 & $3.84 \mathrm{E}-02$ \\
\hline \multirow[t]{11}{*}{ Series 2} & \multirow[t]{9}{*}{ Dim. I } & STL & 0.9837531 & $2.56 \mathrm{E}=10$ \\
\hline & & FWW & 0.9768257 & $2.13 \mathrm{E} \cdot 09$ \\
\hline & & $\mathrm{TL}$ & 0.9606547 & $4.92 \mathrm{E} \cdot 08$ \\
\hline & & FWR & 0.9554717 & $1.02 \mathrm{E}-07$ \\
\hline & & BL & 0.9534827 & $1.32 \mathrm{E}-07$ \\
\hline & & SBL & 0.9486871 & $2.36 \mathrm{E} \cdot 07$ \\
\hline & & FWW & 0.9114634 & $5.73 \mathrm{E}-00$ \\
\hline & & SL & 0.7266371 & $3.24 \mathrm{E}-03$ \\
\hline & & FWW FWR & -0.7043451 & $4.92 \mathrm{E}-03$ \\
\hline & \multirow[t]{2}{*}{ Dím. 2} & SSL & 0.8421097 & $1.58 \mathrm{E}-04$ \\
\hline & & SL & 0.5358381 & $4.83 \mathrm{E}-02$ \\
\hline
\end{tabular}


SUPPL. 6

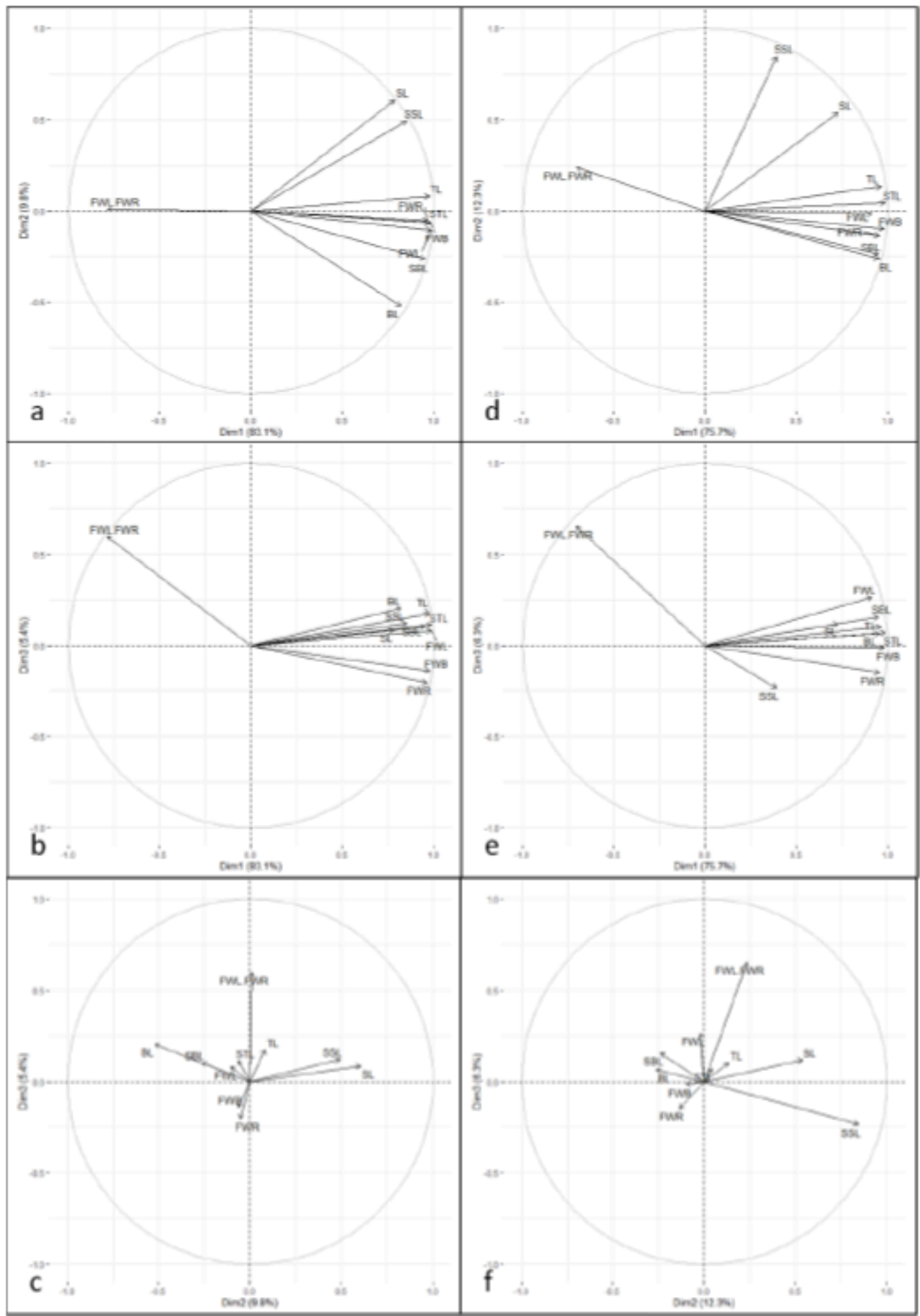

Figure 16: PCA results for Series1 (a, b, c) and Series2 (d, e, f). 
In the figures below, the red dot marks the beginning of a day. Each day starts with watering for a variable time (see SUPPL. 2, Table 9), before LEDs are turned on.

The black arrows show the evolution of $\mathrm{CO}_{2}$ concentration over a period of $24 \mathrm{~h}$. They are labelled with numbers standing out for:

1: High respiration rate just after the plants receive their daily watering.

2: Photosynthesis that ends after $12 \mathrm{~h}$ due to photoinhibition.

3: Low respiration rate until the next watering the following day.

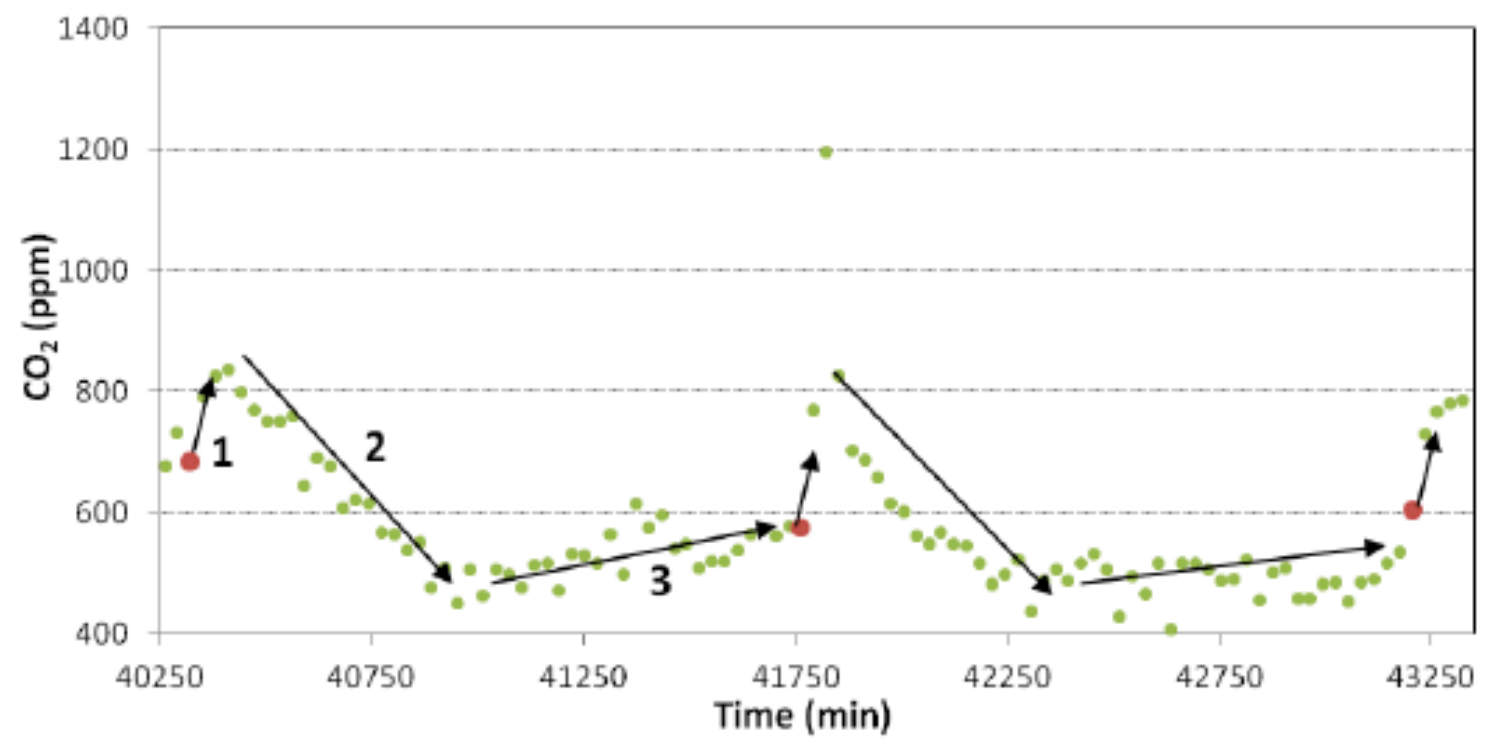

Figure 17: Daily variations $\mathrm{CO}_{2}$ concentration in the $2 \mathrm{U}$ incubator for Day 28 and Day 29 .

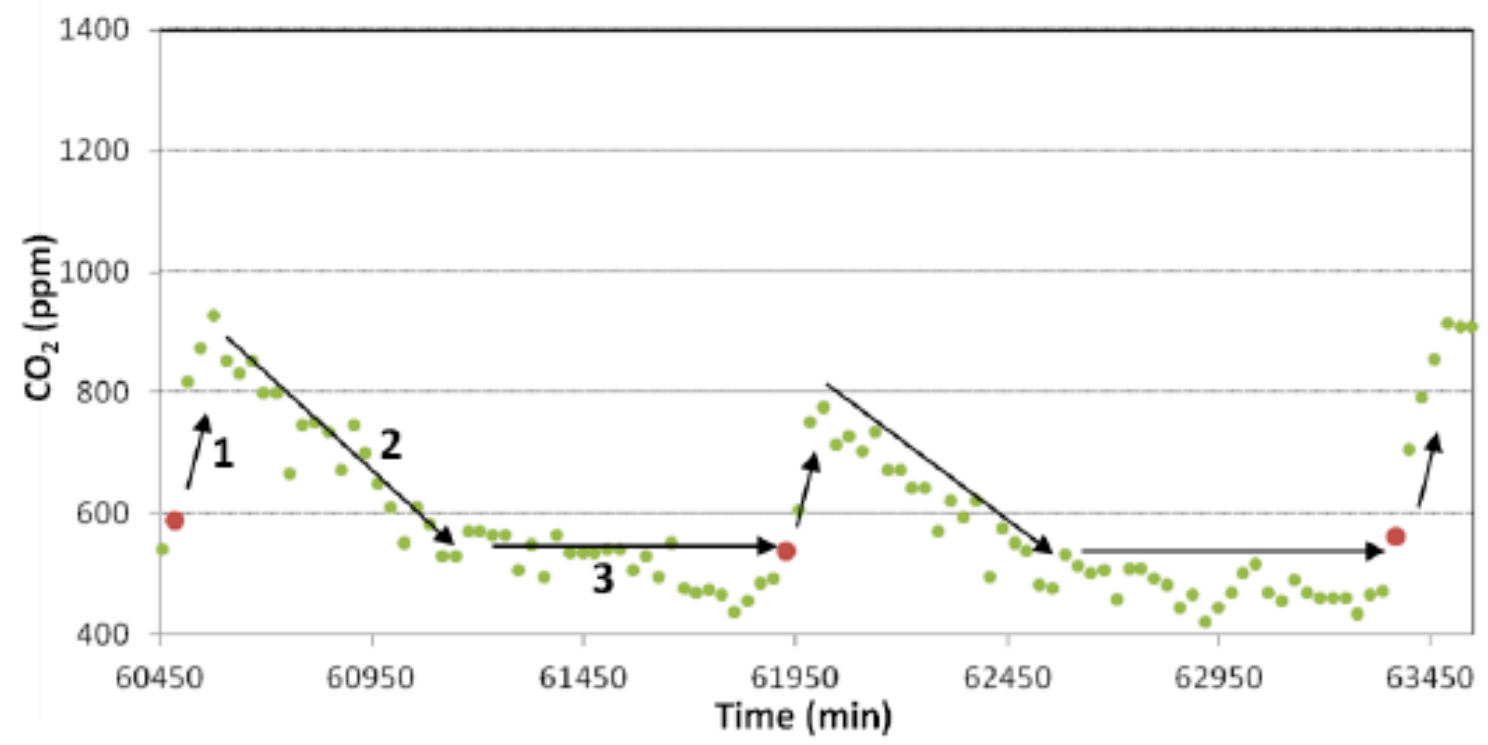

Figure 18: Daily variations $\mathrm{CO}_{2}$ concentration in the $2 \mathrm{U}$ incubator for Day 42 and Day 43. 
Plants after 62 days cultivation into the $2 \mathrm{U}$ incubator.

Left: General view of the plants into the incubator, emerging from the packsoil. We can see top left the ethylene catalyst with its fan. On the top, we have the camera and the LEDs. At the background, there is the flexible heater and below the $\mathrm{O}_{2}$ sensor. On the right, we have the ethylene, $\mathrm{CO}_{2}$, humidity and temperature sensors. Below the packsoil, we have the water tank and in between there is the peristaltic pump and watering tubes. On this picture, we can see that the roots drills holes through the membrane and spread in the interspace below the packsoil.

Right: The shoot of one senescent plant on which we can still see reddish and greenish leaves.
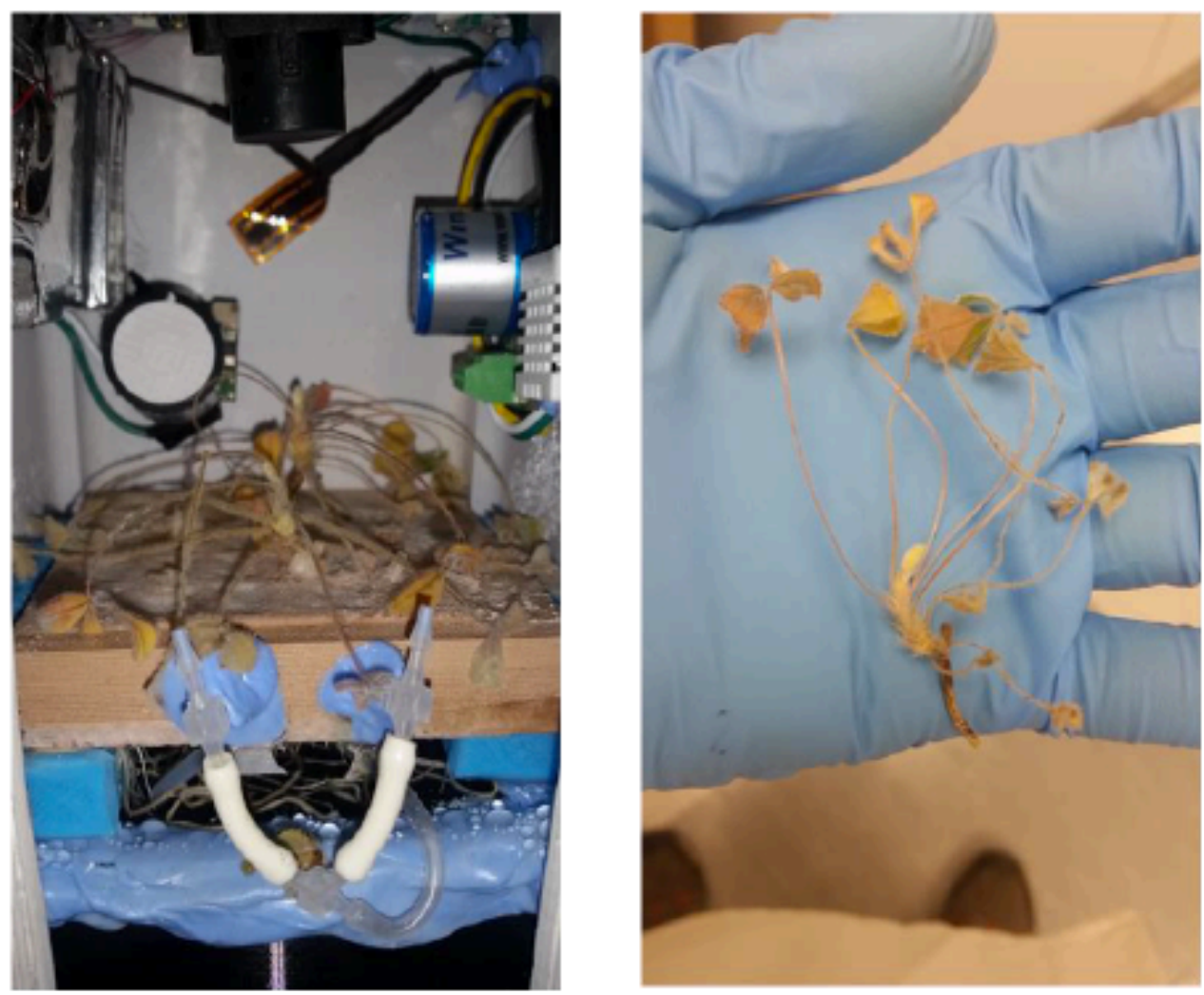

Figure 19: Plants that have grown into the incubator before and after harvesting.

Table 11: Correlation matrix between plants functional traits variables.

\begin{tabular}{lcccccccc}
\hline & FWL & FWR & FWB & BL & SL & TL & SBL & SSL \\
FWR & 0.84 & & & & & & & \\
FWB & 0.93 & 0.98 & & & & & & \\
BL & 0.88 & 0.92 & 0.94 & & & & & \\
SL & 0.59 & 0.59 & 0.61 & 0.55 & & & & \\
TL & 0.84 & 0.87 & 0.89 & 0.89 & 0.87 & & & \\
SBL & 0.9 & 0.9 & 0.93 & 0.98 & 0.58 & 0.9 & & \\
SSL & 0.34 & 0.3 & 0.33 & 0.14 & 0.59 & 0.4 & 0.14 & \\
STL & 0.92 & 0.91 & 0.95 & 0.94 & 0.71 & 0.94 & 0.95 & 0.43 \\
\hline
\end{tabular}




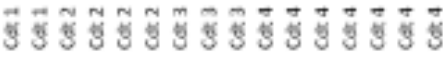

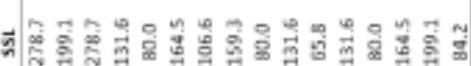

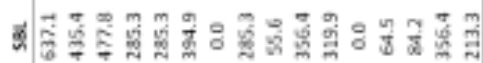

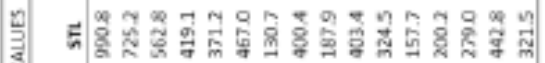

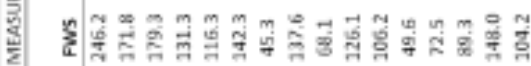

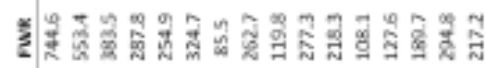

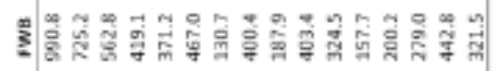

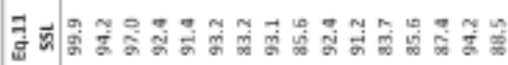

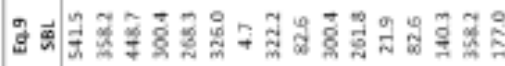

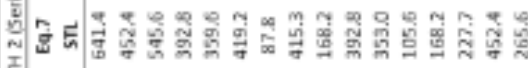

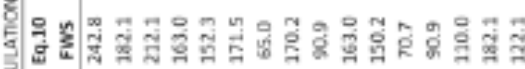
है

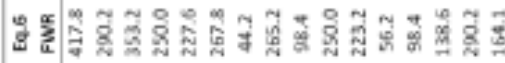

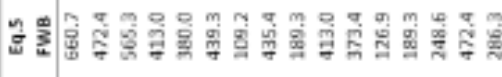

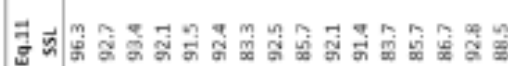

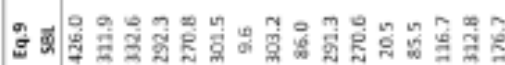
宛

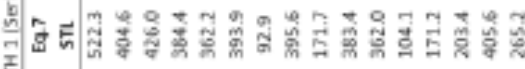
敦。

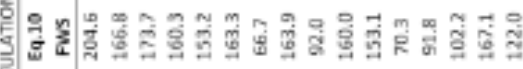
क)

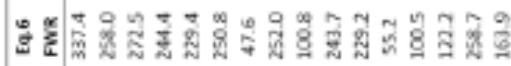

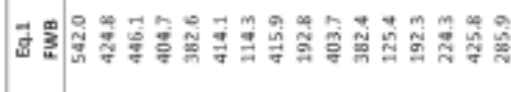

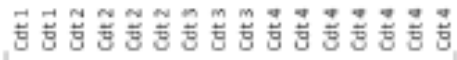

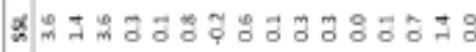

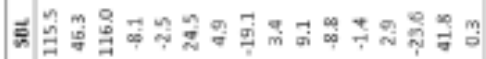

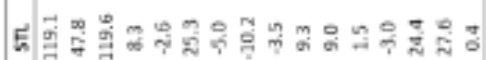

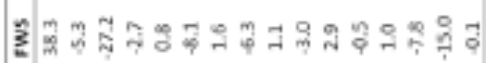

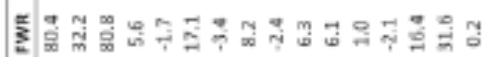
a

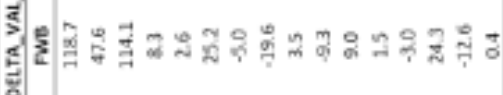

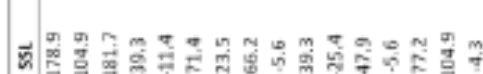

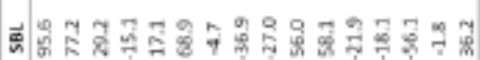

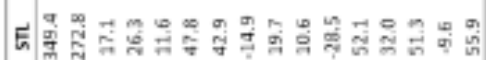

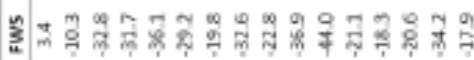

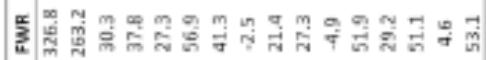

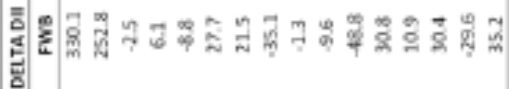

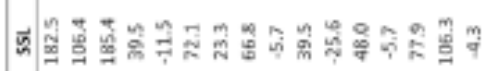

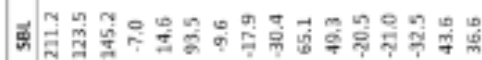

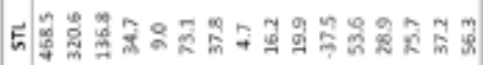

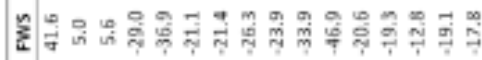

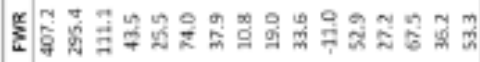

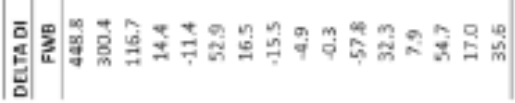

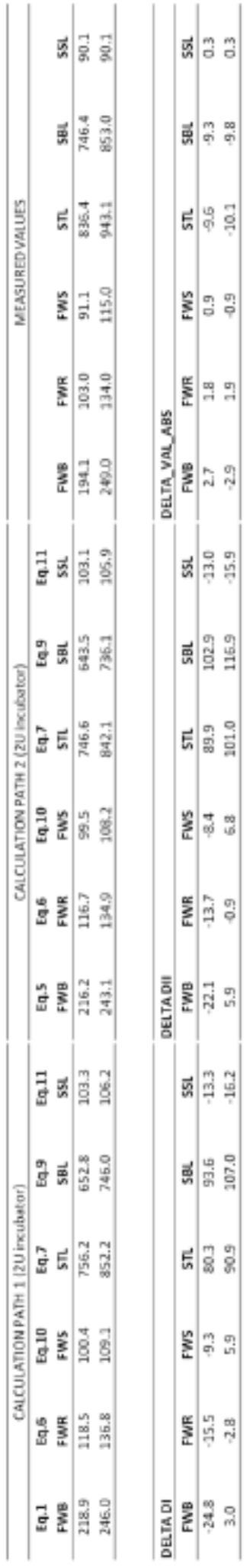

Figure 20: Tables showing the results of calculations done with the model on Series1 and on the 2U incubator. 